مجلة علوم الإنسان والمجتمع................................... حميدي، الباحث: عبد المليك حميدي

\title{
الخطوات الأساسية في البحوث الاجتماعية
}

الدكتورة: سامية حميدي، جامعة بسكرة، الجزائر

الباحث: عبد المليك حميدي، جامعة المسيلة

الللخص

لا يخفى على أي ناشط في ميدان البحث العلمي أن دراسته لأي ظاهرة

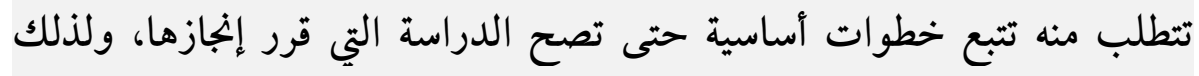

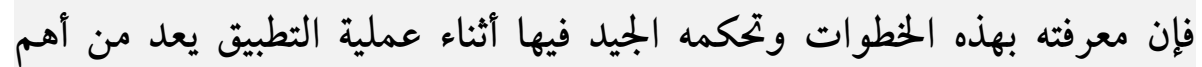

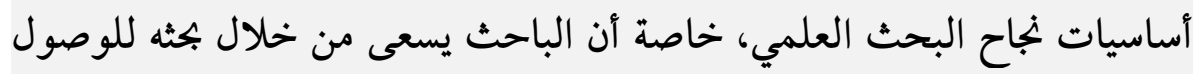

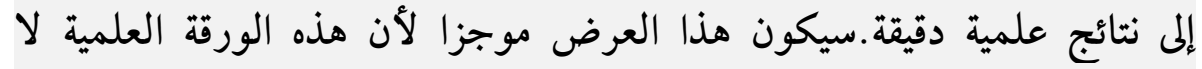

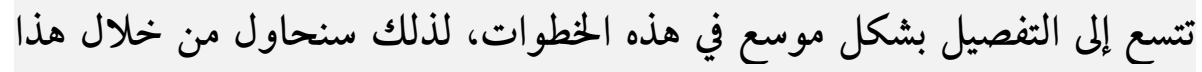

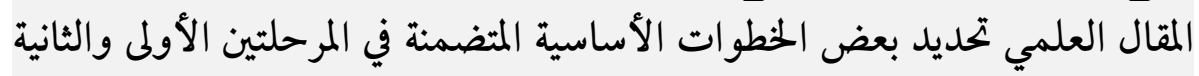
من مراحل البحث العلمي في العلوم الاجتماعية.

\section{Summary}

There is no doubt that the scientific research to any phenomenon requires of the researcher to follow the basic steps for the accuracy of the study. Knowing these steps and enables the researcher them well during the application process is one of the most important basics success of scientific research, especially that the researcher seeks access to accurate scientific results. This article will introduce those steps briefly away from the detail, by identifying some of the basic steps in the first and second phases of the stages of scientific research in the social sciences. 
اكتسى البحث العلمي في الآونة الأخيرة أهمية بالغة بسبب تطور

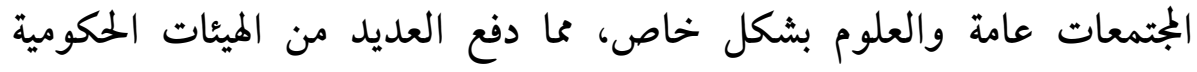

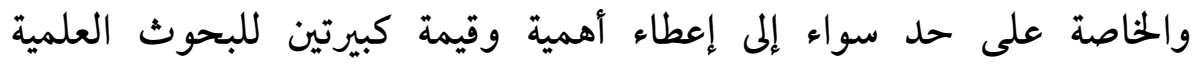

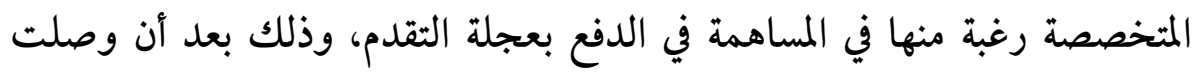

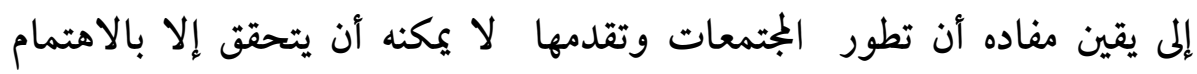

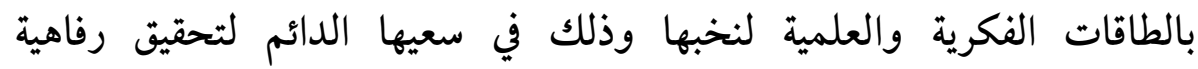

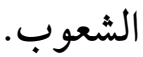

لقد أصبحنا في الوقت الراهن في حاجة ماسة إلى الدراسات والبحوث المعند

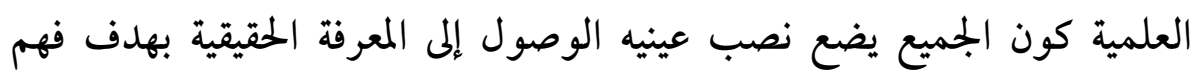

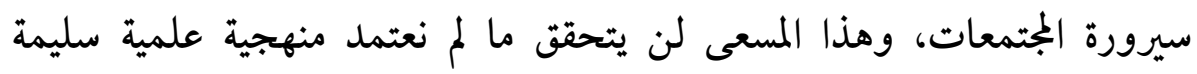

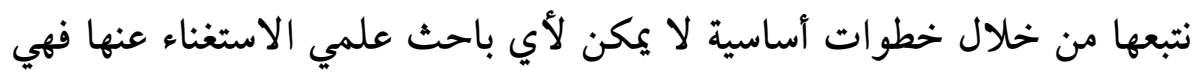

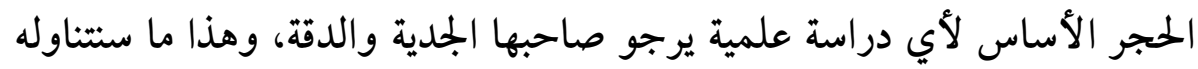

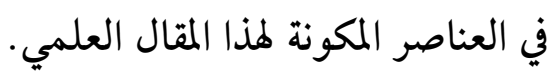

أولا/ الإشكاليــــــة

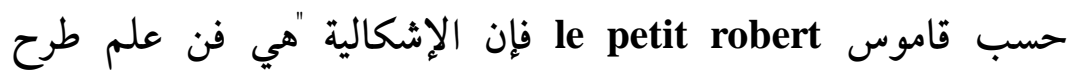

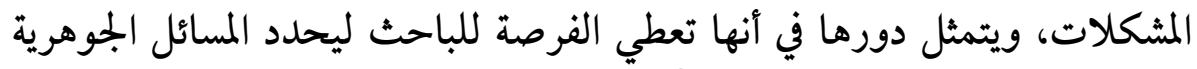

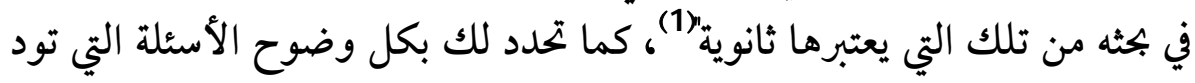

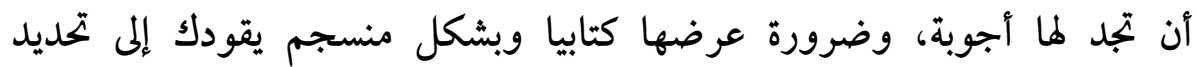

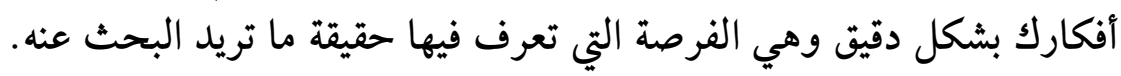

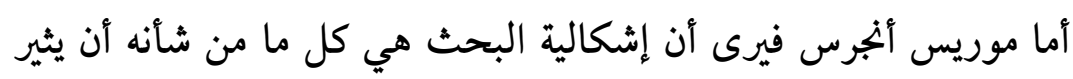

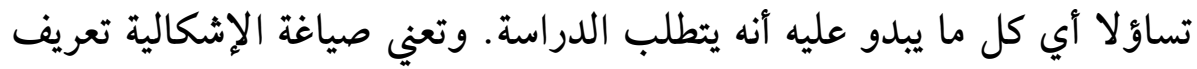

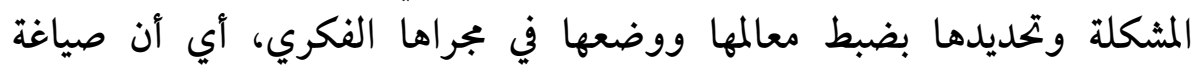

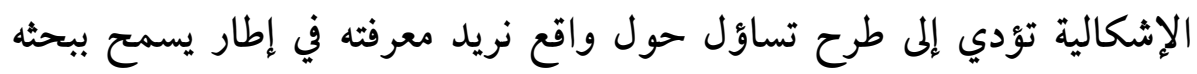




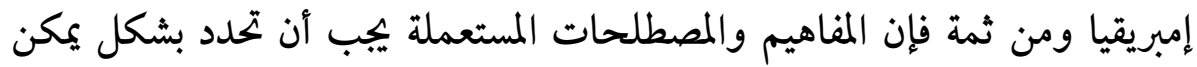

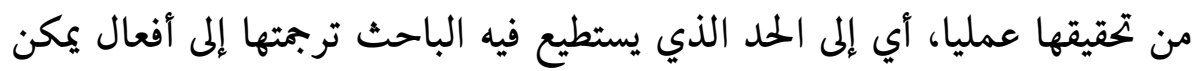
ملاحظتها في الواقع. يضع بعض الباحثين تفرقة بين المشكلة والإشكالية نخصرها فيما يلي:

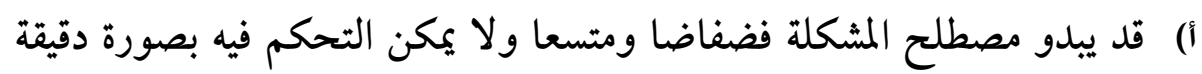

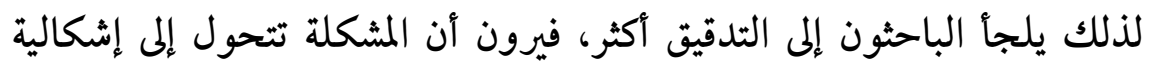

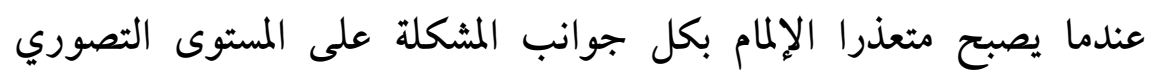

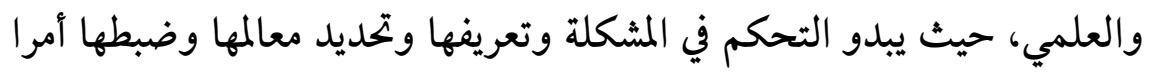

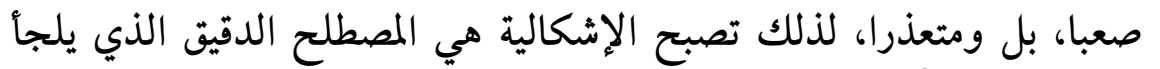
إليه الباحثون. (2) ب) الإشكالية هي المدخل النظري الذي يقر البرا الباحث تبنيه لمعالجة المثكلة التي

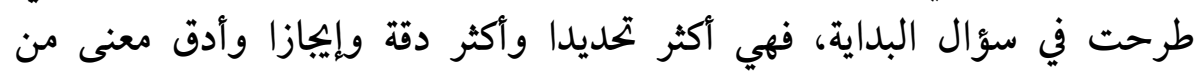

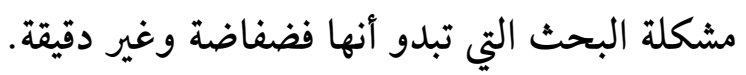

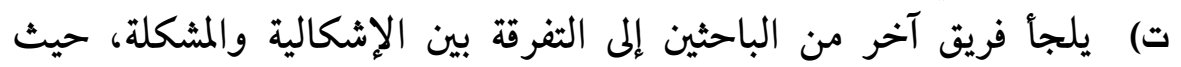

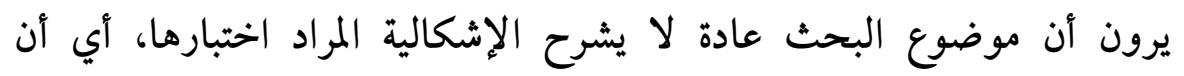

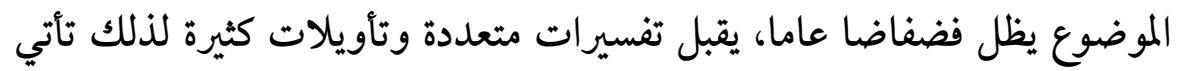

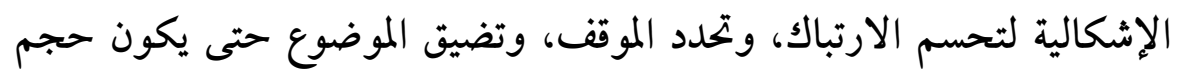

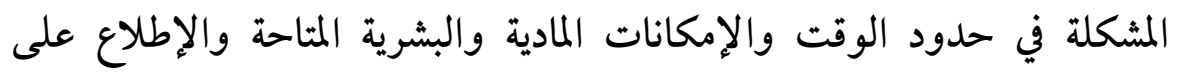

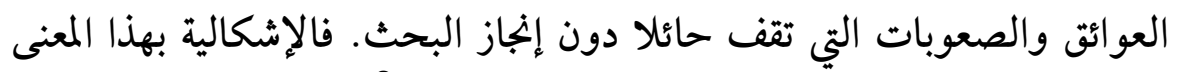

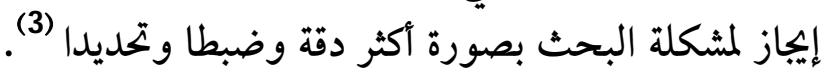

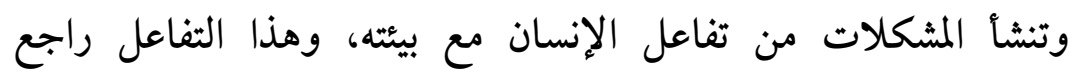

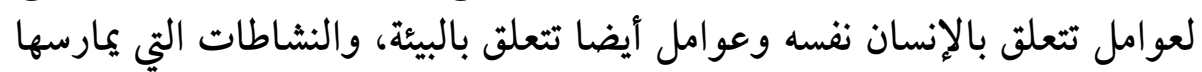

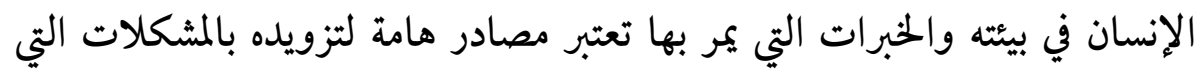

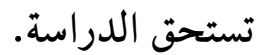


أ) الخبرة العلمية: يواجه الإنسان في حياته اليومية عدة مواقف وصعوبات

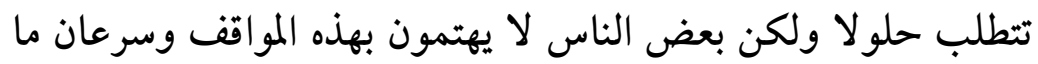

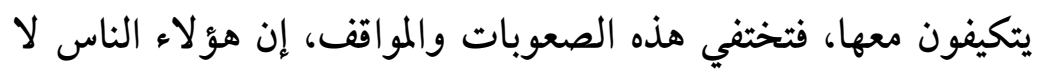

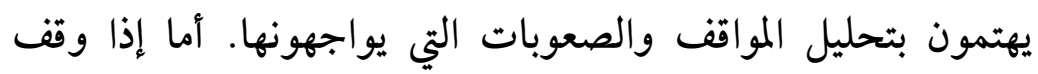

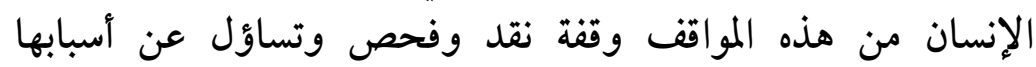
ودوافعها وشعر بالقلق تجاهها فإنه يجد فيها مشكان ونكلات تستحق

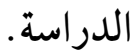

ب) القراءات والدراسات: كثيرا ما نجد في قراءاتنا ودراساتنا مواقف مثيرة لا الا

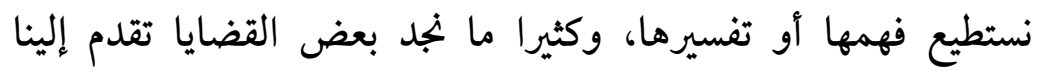

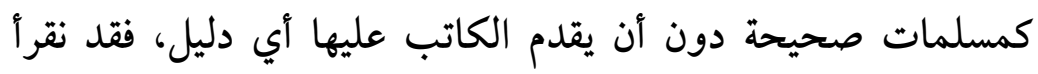

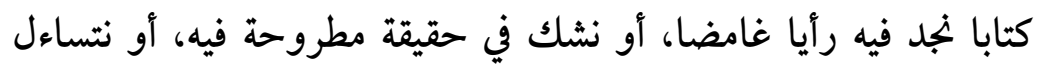

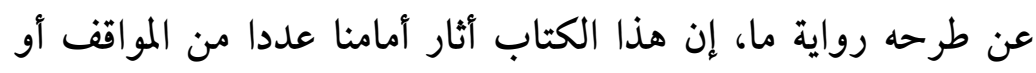

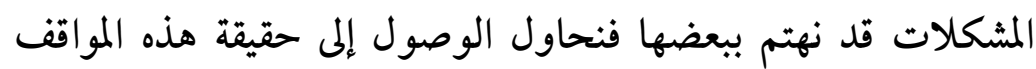

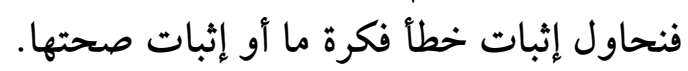

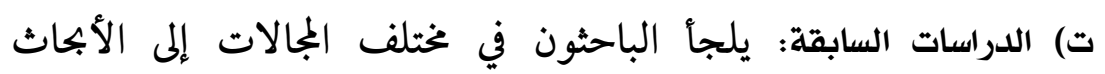

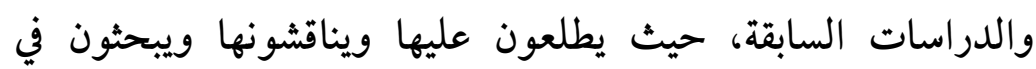

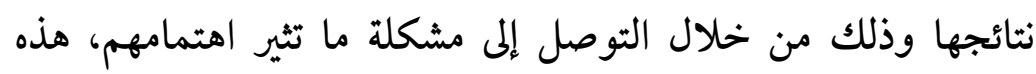

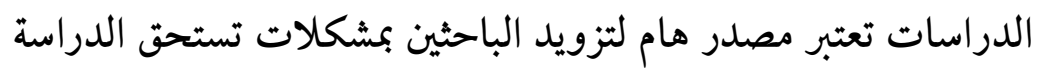

\section{- مراحل بناء الإشكالية}

أ) المرحلة الأولى: مرحلة ضبط وجهات الإلية النظر المختلفة حول الموضوع: في هذه

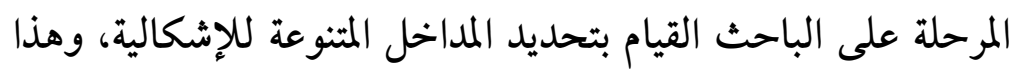

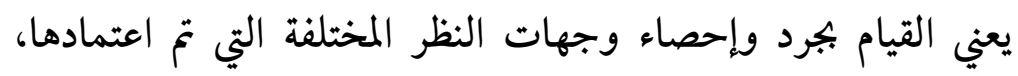

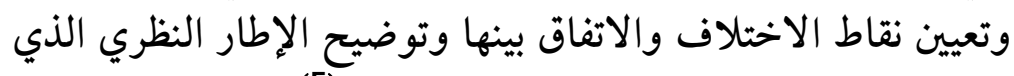

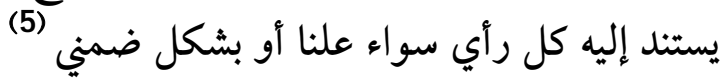


ب) المرحلة الثانية: تبني إشكالية: في هذه المرحلة لابد من تبني إشكالية

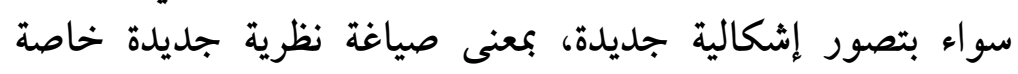

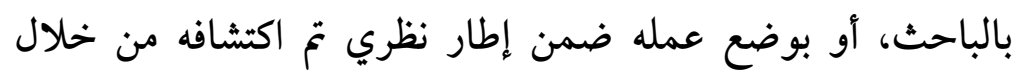

$$
\text { القراءات السابقة. }
$$

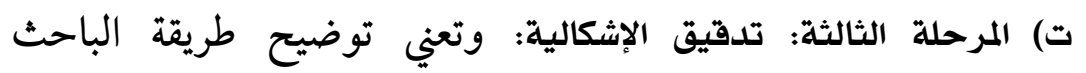

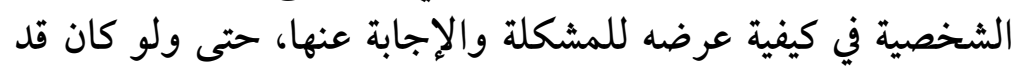

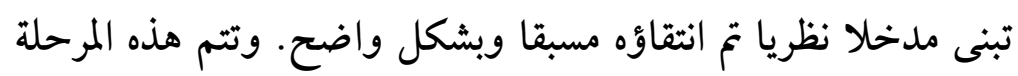

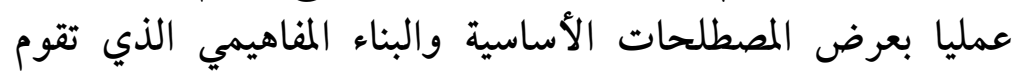

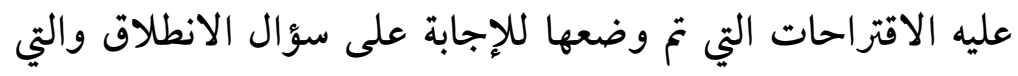
تأخذ شكلها من خلال البناء.

\section{يمكن تلخيص الخطوات المنهجية المتبعة في صياغة الإشكالية فيما يلي:}

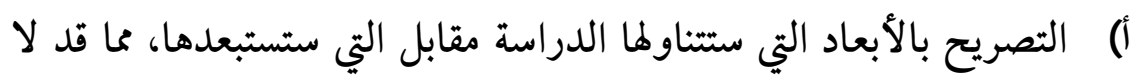

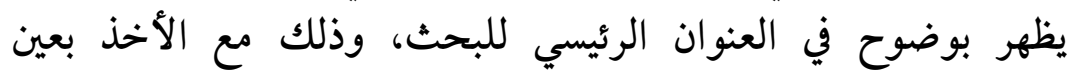

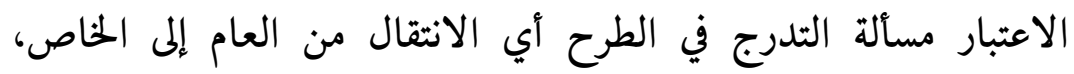

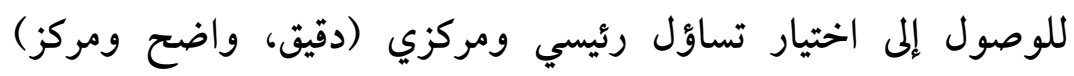

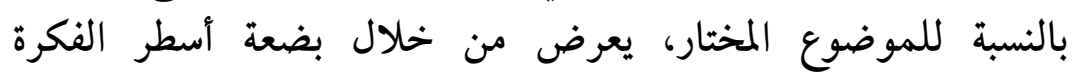
الأساسية في البحث والتي تسمح مبدئيا بتعميق العنوان وتحديد بلديده بدرة الفركة

$$
\text { أكثر. }
$$

ب) توضيح الأسباب والدوافع التي قادت الباحث للقيام بها.

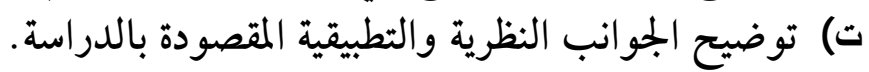

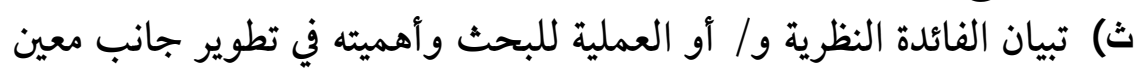

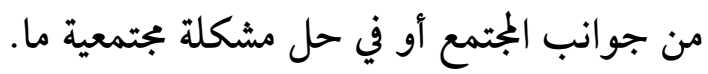
ج) تحديد الإطار النظري للبحث أي الخدلفي البلفية النظرية (نظريات، مدارس فكرية) التي يعتمد عليها الباحث مع التبرير. 
ثانيا/ الفرضيــــــات

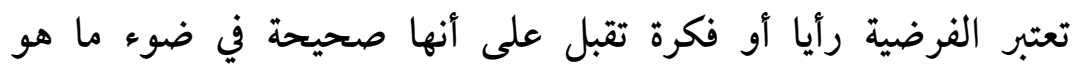

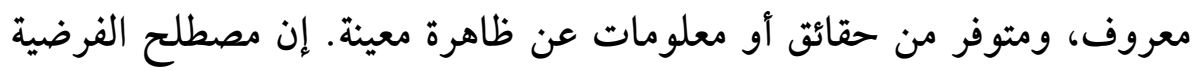

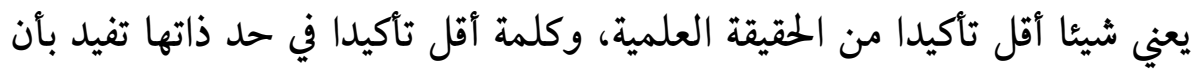

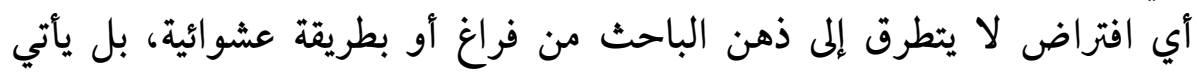

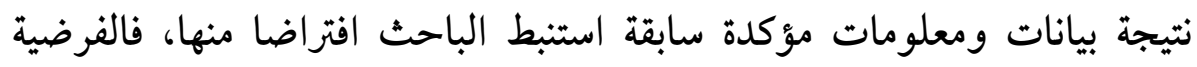

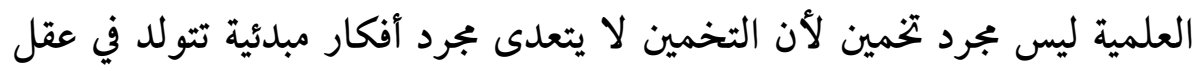

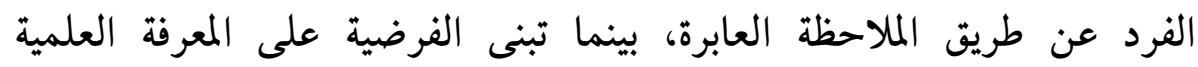

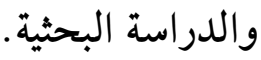

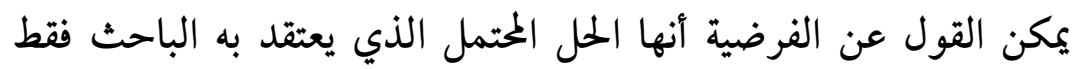

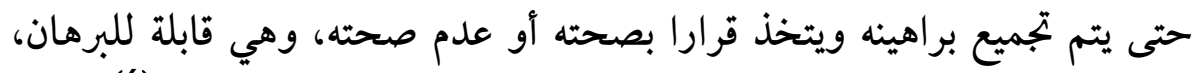

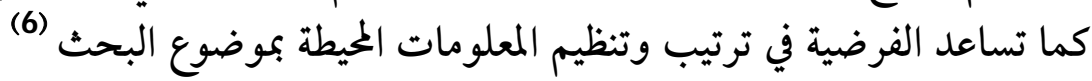
كما تعرف الفرضية على أنها عبارة عن جملة تعبر عن تخمين أو استنتاج

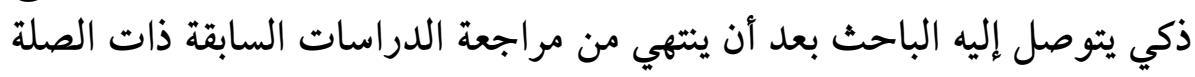

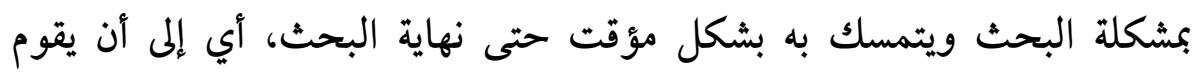
بالتحقق من صحته لقبوله أو رفضه. كما تعرف بأكثر من شكل بـ من منها: أ- ال مل محتمل لمشكلة البحث. ب- تخمين ذكي لسبب أو أسباب المشكلة. ت- رأي مبدئي لحل المشكلة. ثـ إجابة محتملة عن السؤال الذي تمثله المثكلة.

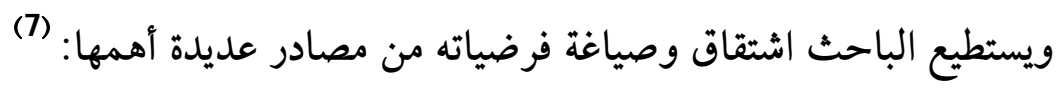

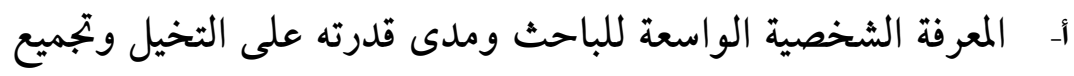
وربط الأفكار مع بعضها البعض في أنماط تفسيرية معقولة. 
ب- الملاحظة والتجربة والخبرة العملية خصوصا فيما يتعلق بالمثكلة أو الظاهرة المدروسة. تـ الدراسات السابقة حول المشكلة أو الظاهرة قيد الدراسة.

- أنواع الفرضيات

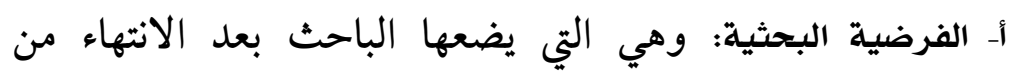

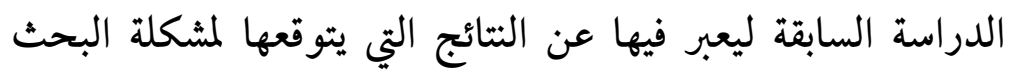
بصورة عامة وتصاغ بما يحتمل الصواب أو الخطأ.

مثال: تزداد فاعلية المعلم في التدريس بارتفاع مستوى تأهيله

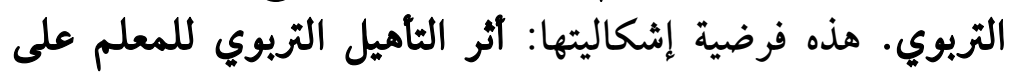
فاعليته في التدريس.

ب- الفرضية الإحصائية: وهي التي تصاغ على شكل جملة خبرية رقمية

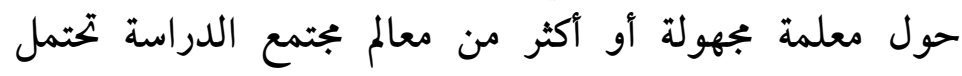

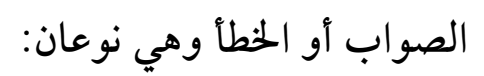

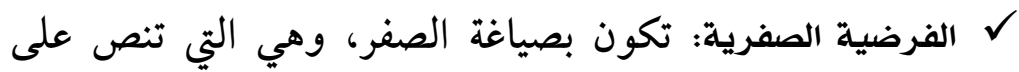
عدم وجود أثر للمعالجة التجريبة (المتغير المستقل) على الميلى المتغير علئ الثابع.

ل الفرضية البديلة: وهي التي يمكن أن تقبل كبديل للفرضية الصفرية عندما يتم رفض الفرضية الصفرية.

وهناك العديد من المعايير التي يجب اتباعها عند صياغة الفرضية نذكر منها: (8) أ- أن تصاغ بشكل يعبر عن العلاقة بين متغيرين أو أكثر.

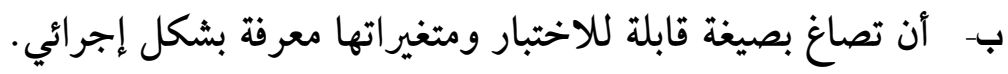

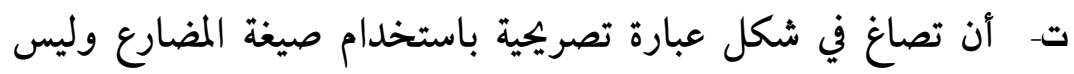
الماضي أو المستقبل. 
ثـ أن تقوم على مبررات كافية مستندة إلى معالجات نظرية أو دراسات سابقة. - مان

- أمميتها

أ - تدعم الإطار النظري والتصوري والفكري للباحث.

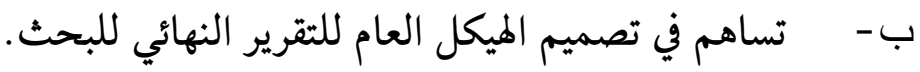
ت - تساعد على حل مشكلة البحث بطريقة علمية سليمة. ث - الكشف عن الحقائق العلمية.

ثالثا/ التحليل المفهومي (المفاهيم الاساسية في البحث العلمي) تناول موريس الجرس في كتابه "منهجية البحث العلمي في العلوم الإنسانية"

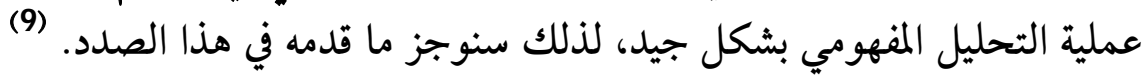

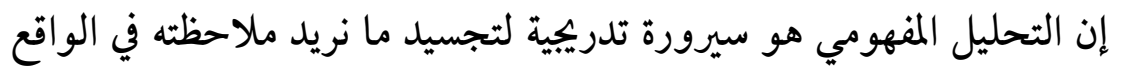

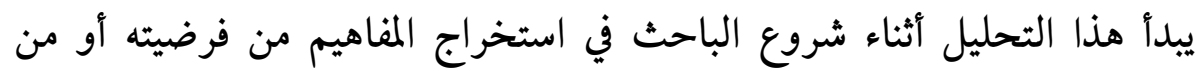

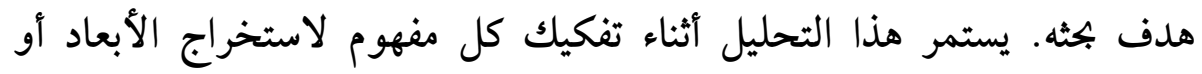

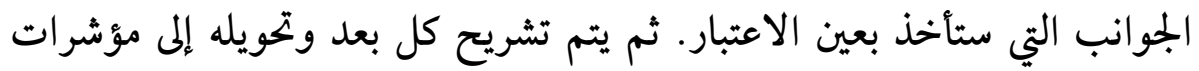

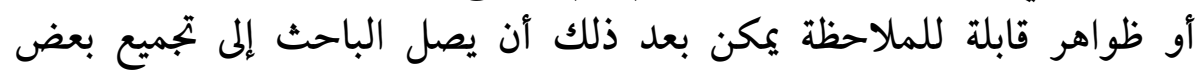

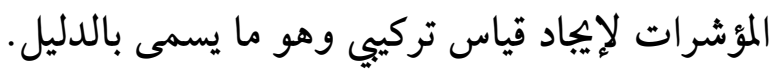

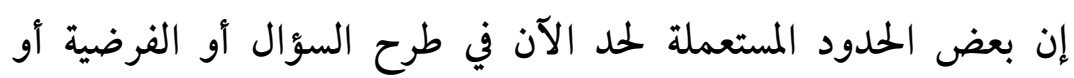

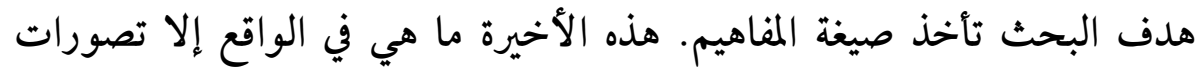

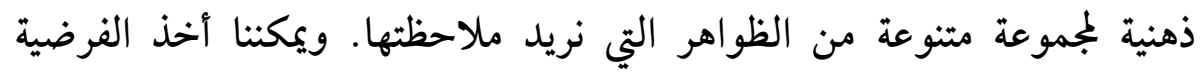

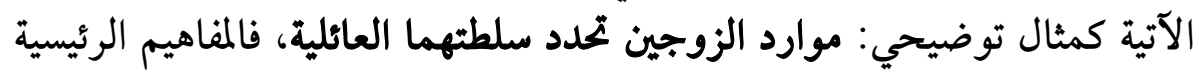

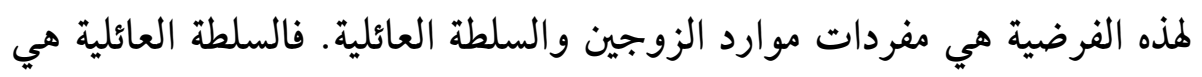

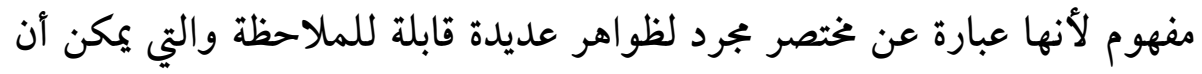

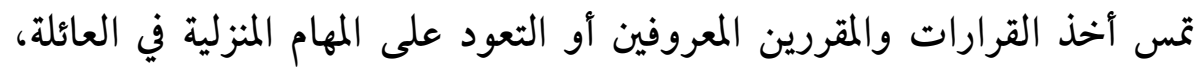

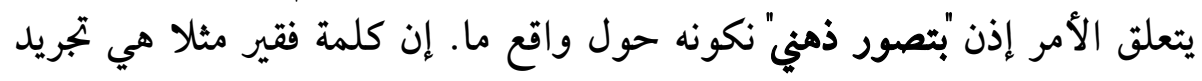




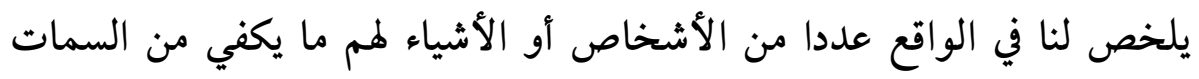

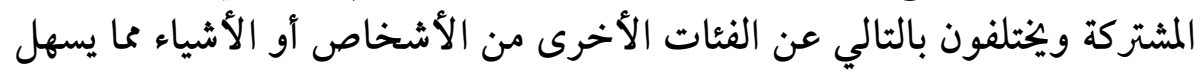

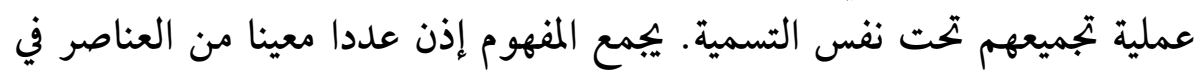
نفس الكلمة أو اللفظ.

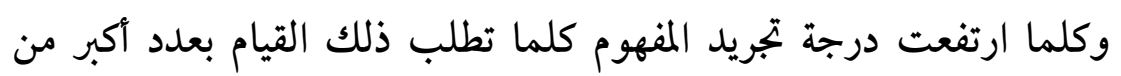

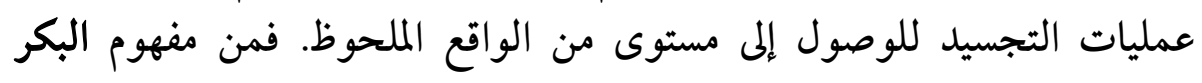

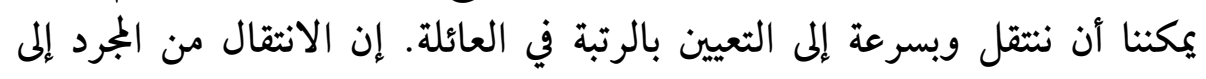

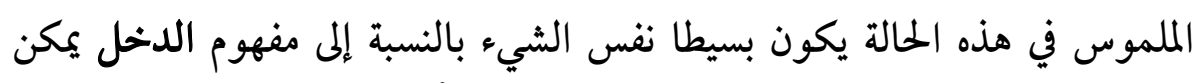

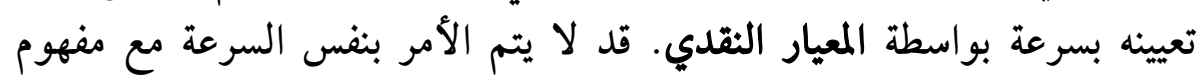

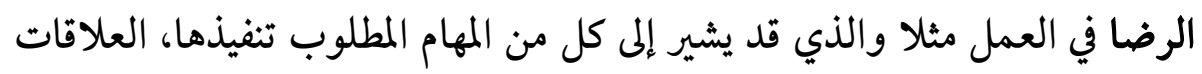

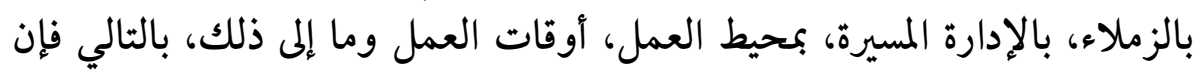

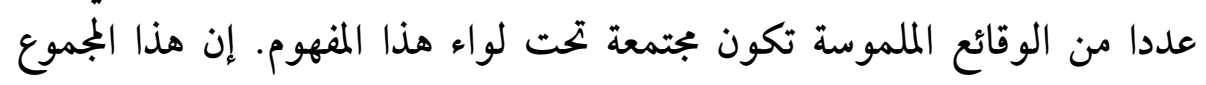
المعقد يعطي معنى للمفهوم أثناء تجسيده في الواقع.

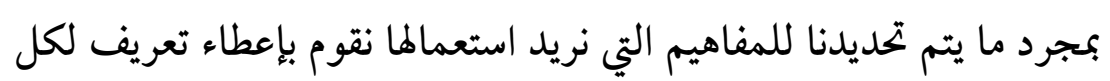

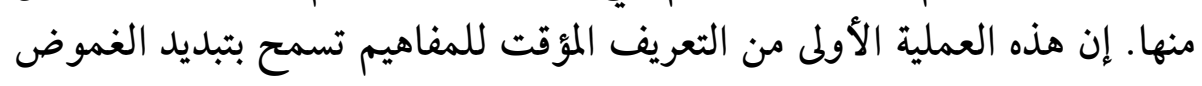

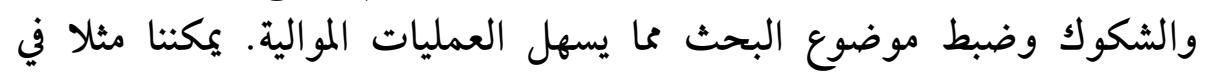

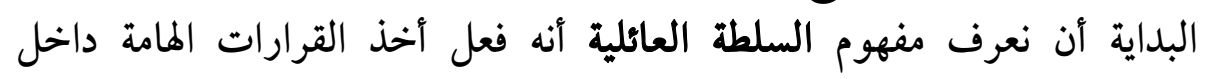

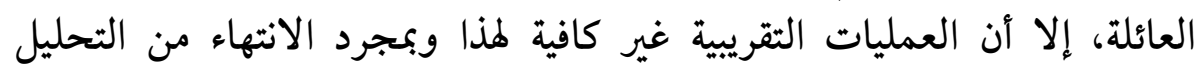

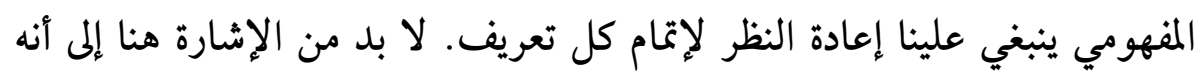

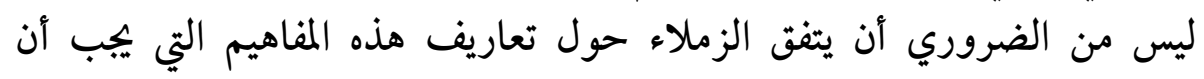

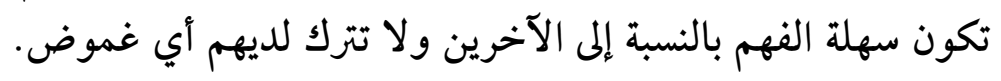

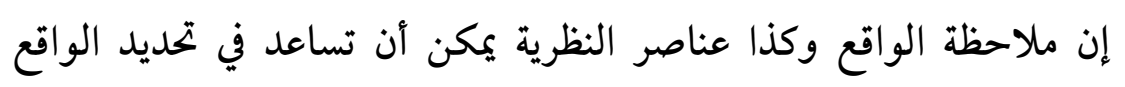

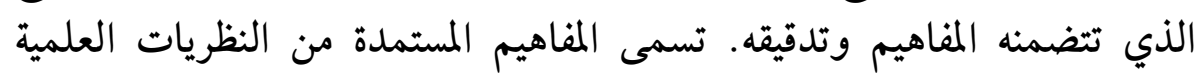

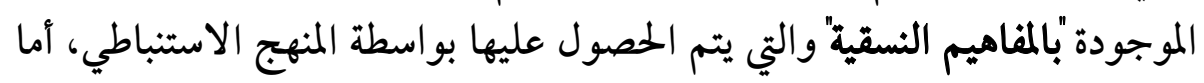

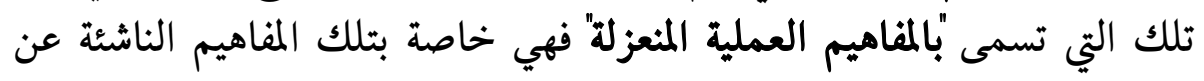


ملاحظة الواقع والتي نتحصل عليها بواسطة المنهج الاستقرائي. إن المفاهيم

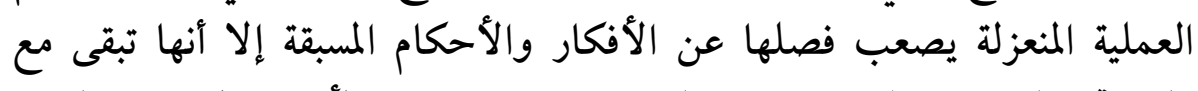

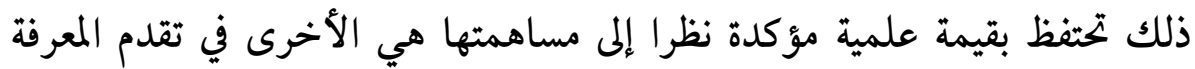
العلمية. هذا هو المسار العادي الذي يسلكه البحث الكيفي.

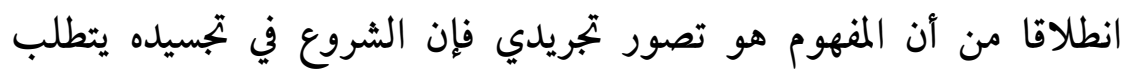

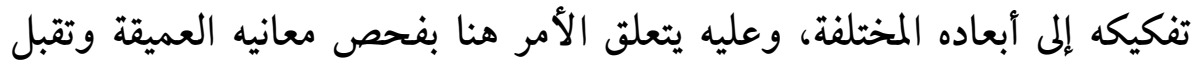

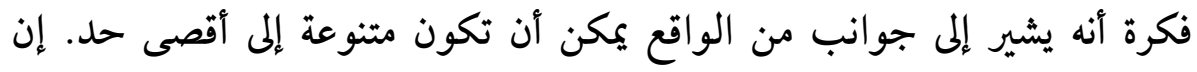

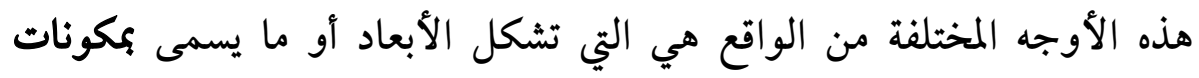

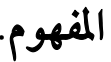

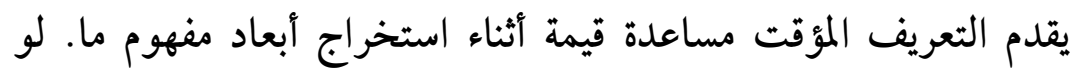

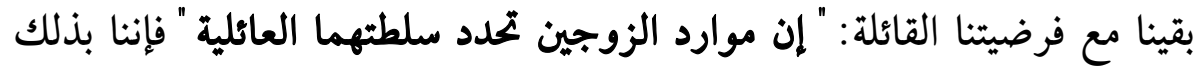

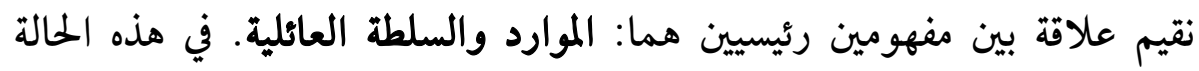

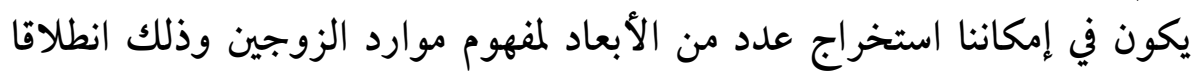

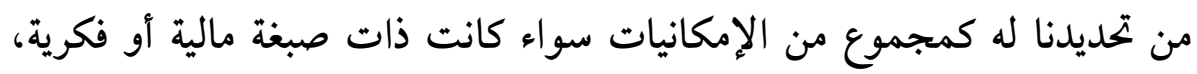

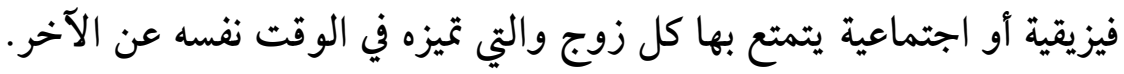

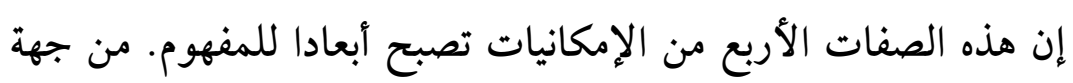

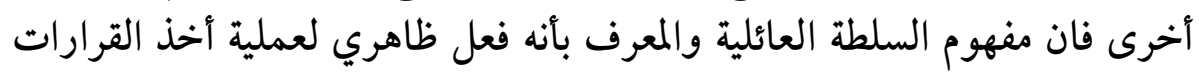

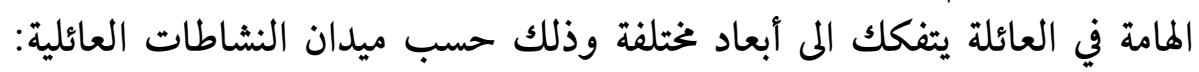

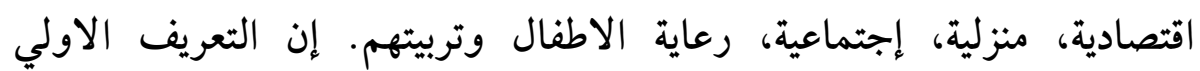

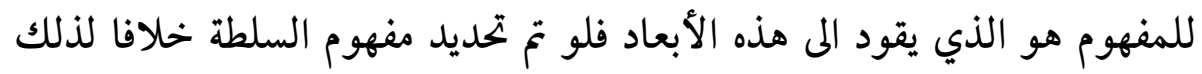

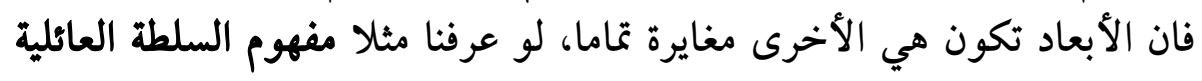

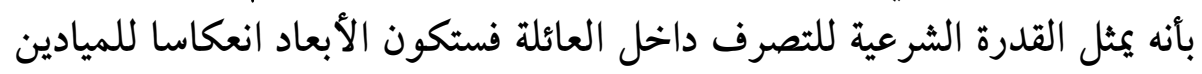
المعترف بها من طرف القانون الذي يسمح بممارسة السلطة على اعضاء العائلة. 
كل ما هو غير ملاحظ ولا يقبل القياس مباشرة سيبقى من صنف الأبعاد

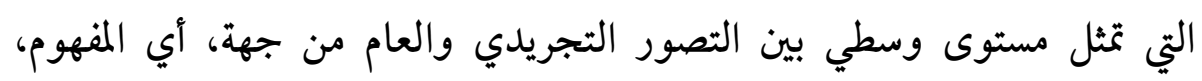

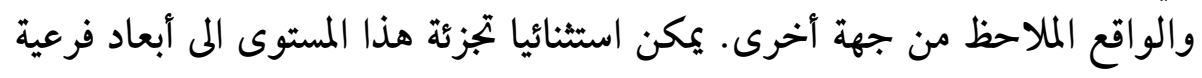

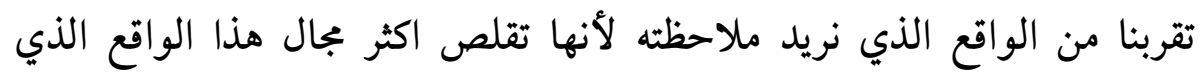

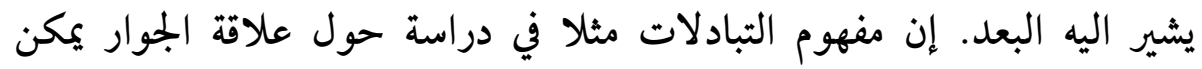

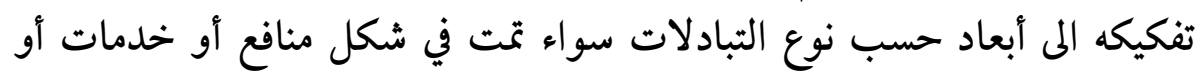

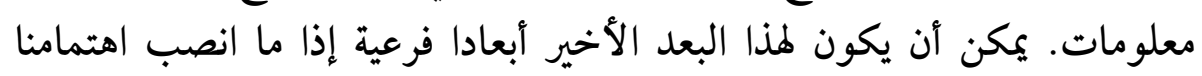
على طبيعة المعلومات المتبادلة، إقتصادية، منزلية أو اجتماعية.

رابعا/ المنـــــاهج:

يعرف المنهج لغة على أنه كلمة منهج مأخوذة من اللاتينية من أصل يوناني

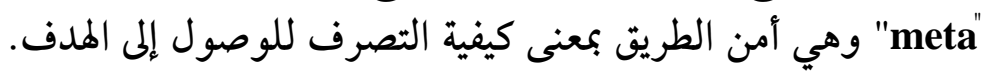

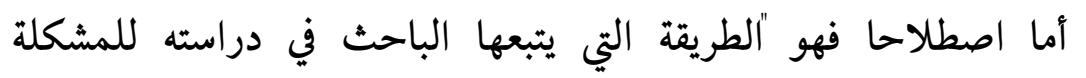

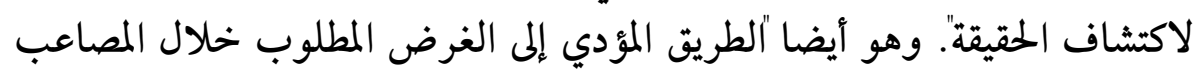

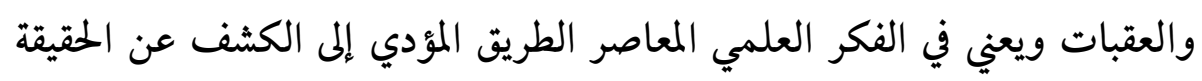

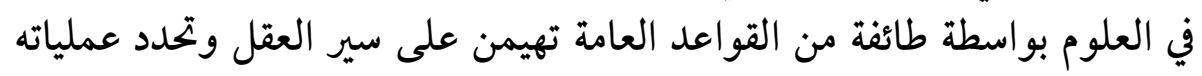

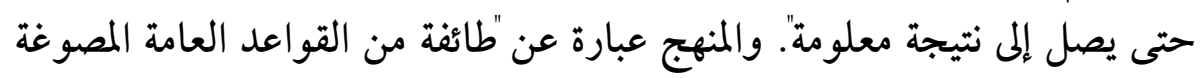

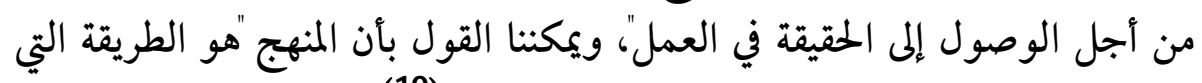

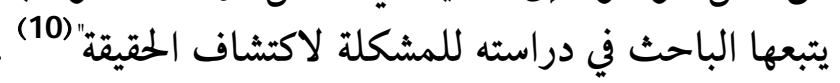

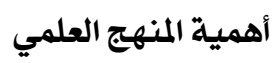

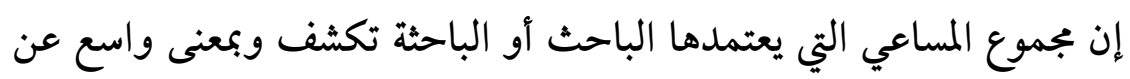

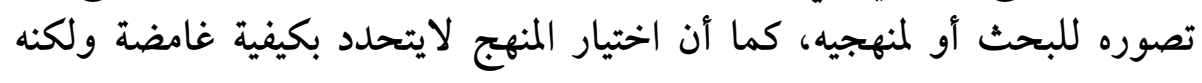

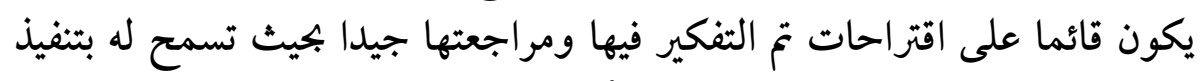

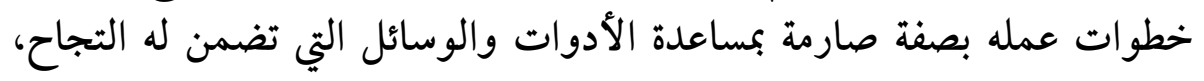
وفي تفس الوقت مدى صحة المسعى أي الطريقة. إن هذين الجانبين أي المنهج التهات 


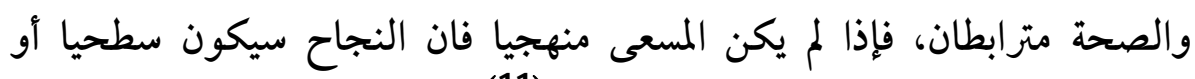
ظاهريا فقط وهنا تكمن أهمية المنهج العلمي (11). 2) (أنواع المناهج

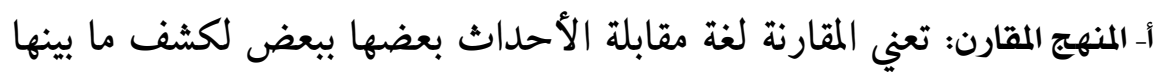

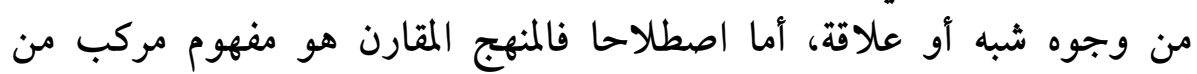

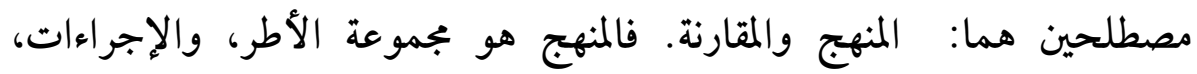

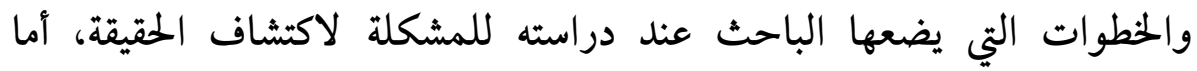

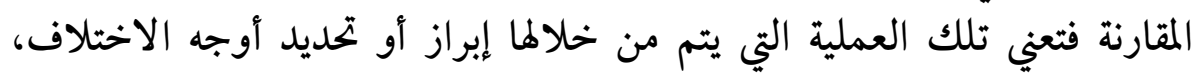
وأوجه الائتلاف بين شيئين متماثلين أو أكثر.

والمنهج المقارن بصفة عامة هو القيام بعملية التناظر أو التقابل بين الأشياء

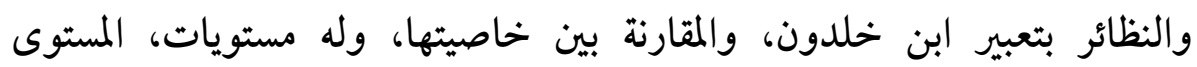

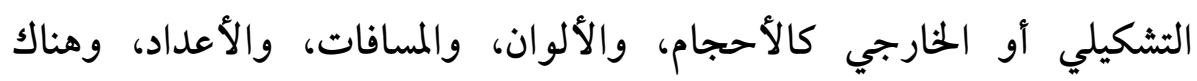

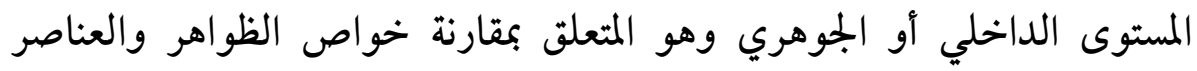

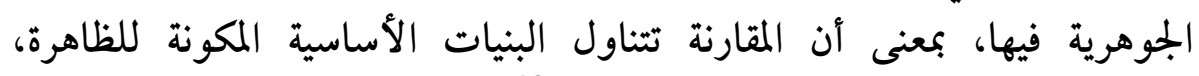
والتعمق وسبر جوهر الظواهر والتمعن فيهان" (12). كما يعرف على أنه طريق لمعالجة الموضوعات ذات ذات الطابع المقارن، أي بيان أوجه

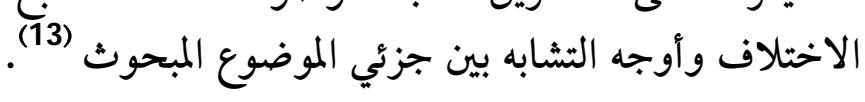

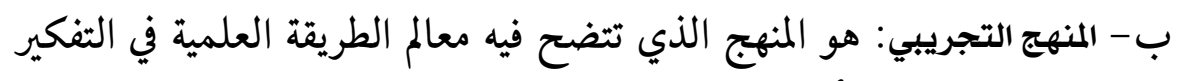

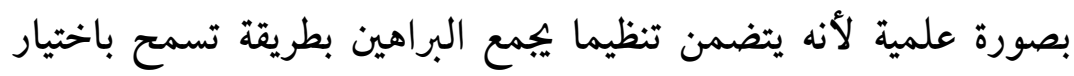

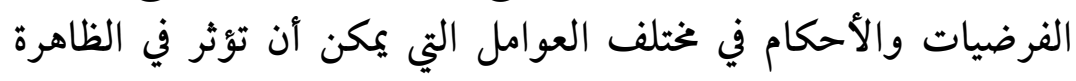

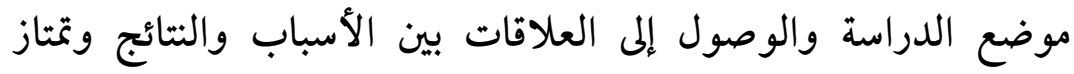

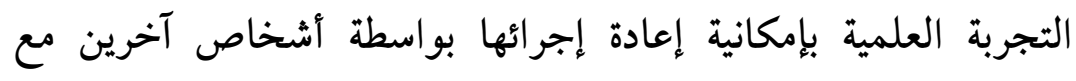

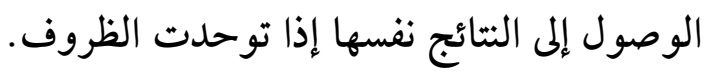




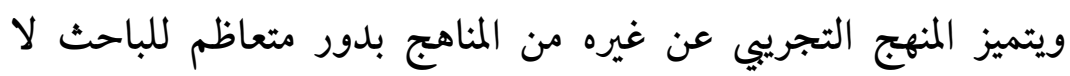

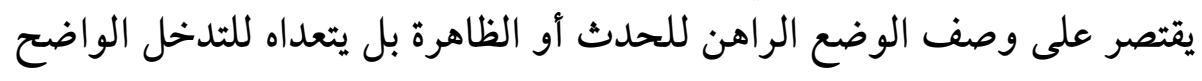

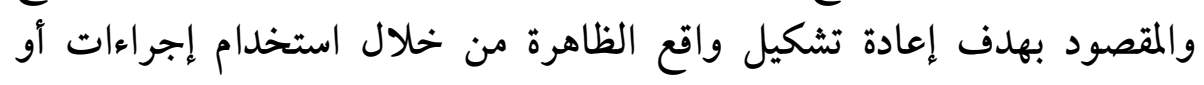

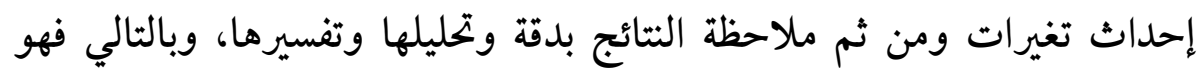

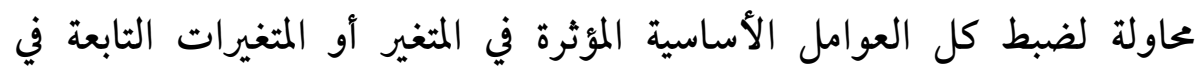

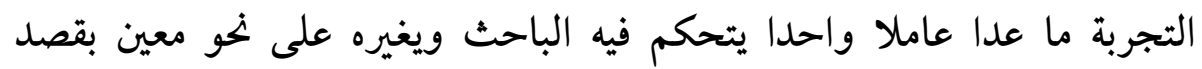

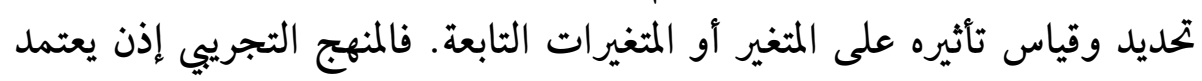

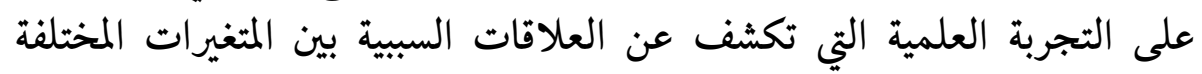

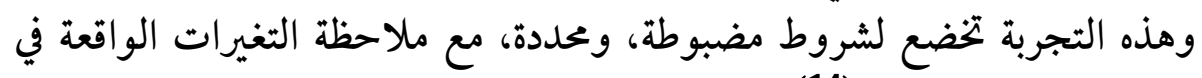

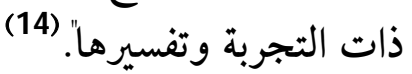

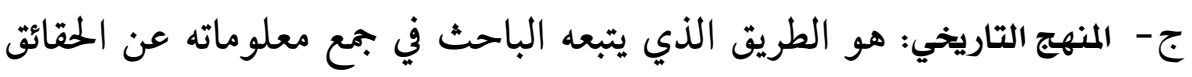

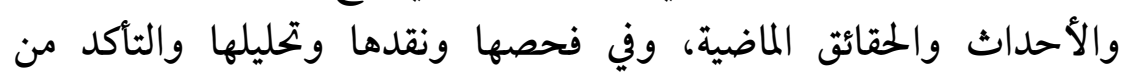

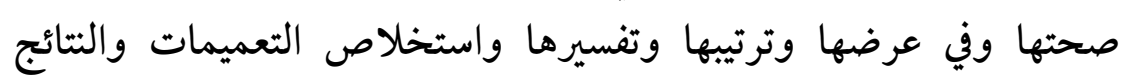

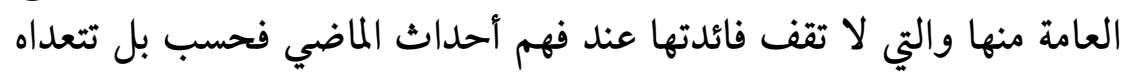

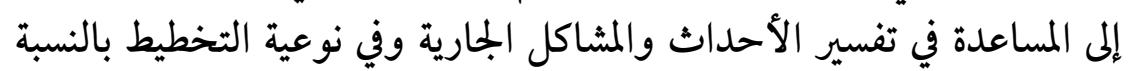
للمستقبل (15)

ويقوم المنهج التاريخي على أساس من الفحص الدقيق والنقد الموضوعي

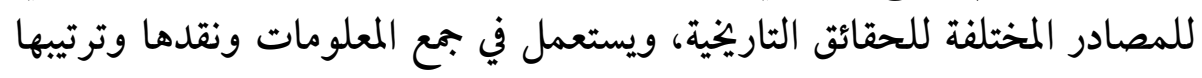

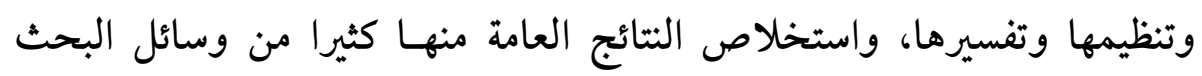

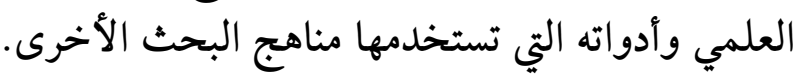

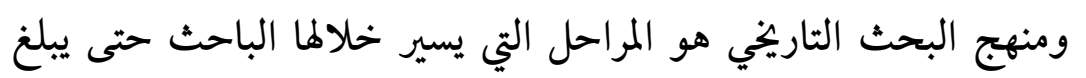

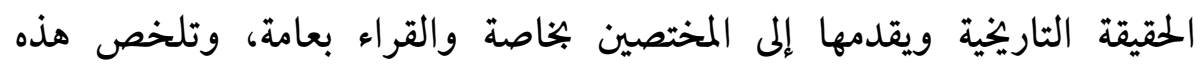

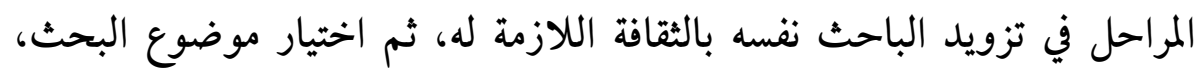

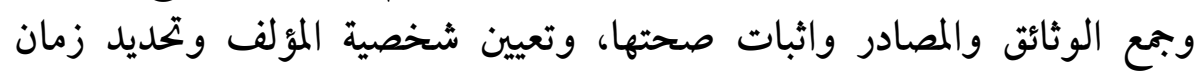
التدوين ومكانه وتحري نصوص الأصوان والمول وتحديد العلاقة بينها، ونقدها نقدا إيجابيا 
وسلبيا واثبات الحقائق التاريخية وتنظيمها وترتيبها والاجتهاد فيها وتعليلها،

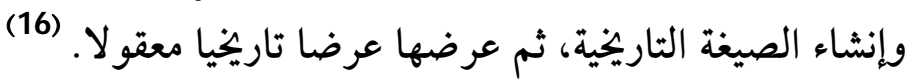

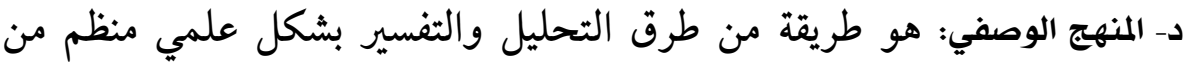

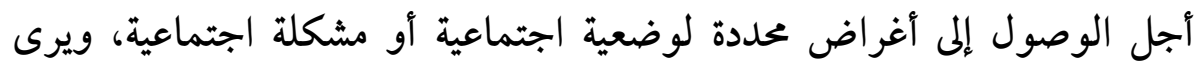
آخرون أن المنهج الوصفي يعتبر طريقة لوصف الظاهرة المدروسة وتصويرها لورها كميا

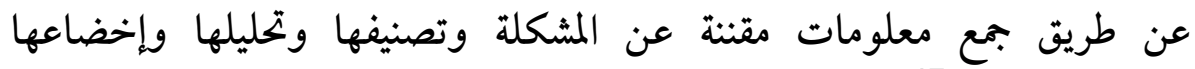
للدراسة الدقيقة (17)

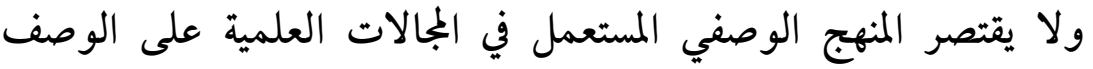

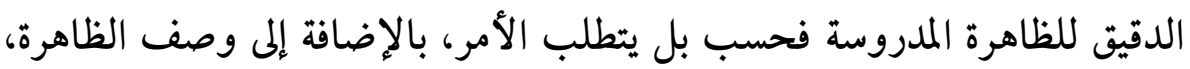
وجمع البيانات عنها ووصف الظروف والممارسات المختلفة تحليل هذه البيانات واستخراج الاستنتاجات، ومقارنة المعطيات وبالتالي التوصل وإن إلى نتائج يمكن

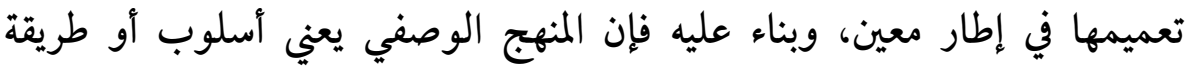

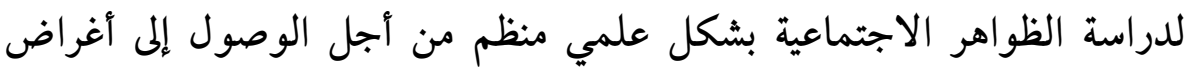

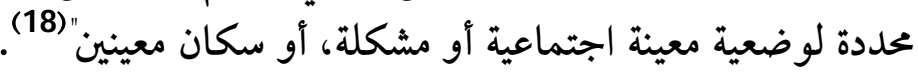

هـ- منهج دراسة الحالة: وهو المنهج الذي يتجه إلى جمع البيانات العلمية المتعلقة

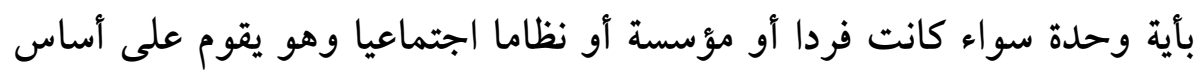

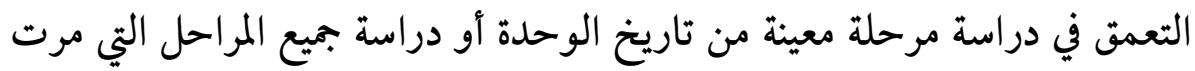

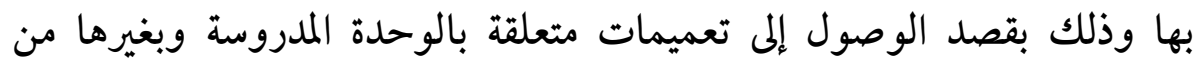
الوحدات المتشابهة.

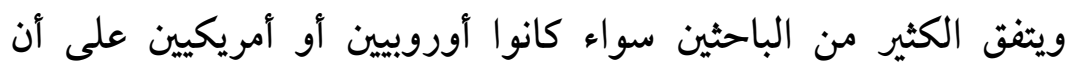

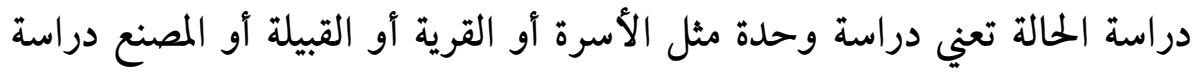

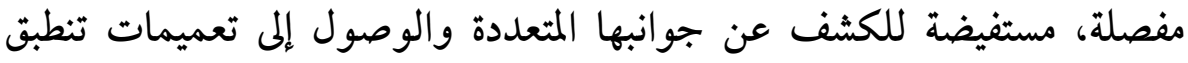

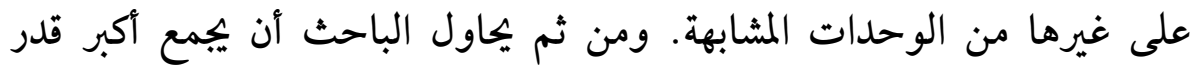

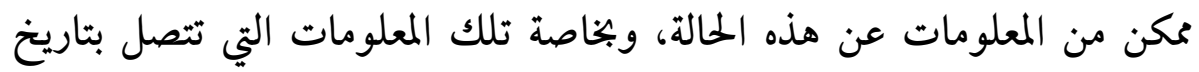




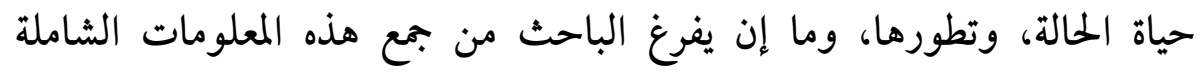

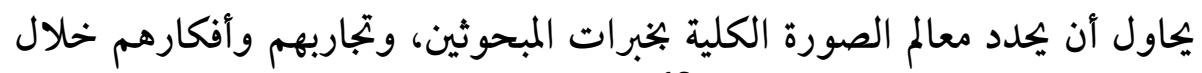
الزمن، وتفسير هذا الموقف الكلي" (19).

خامسا/ العينــــــــات

تعرف العينة على أنها جزء من الكل على أن يكون هذا الجزء ممثلا للكل

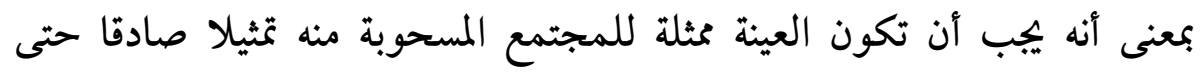

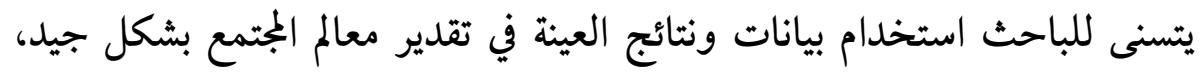

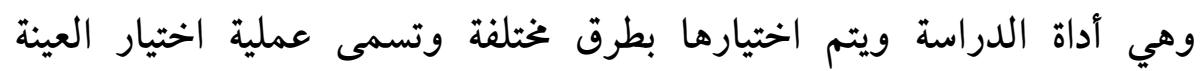
بـألمعاينة."

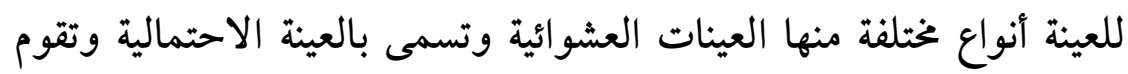

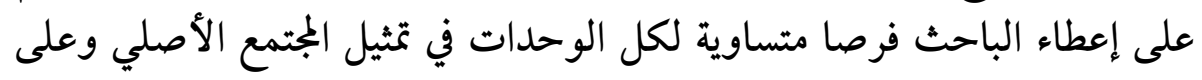

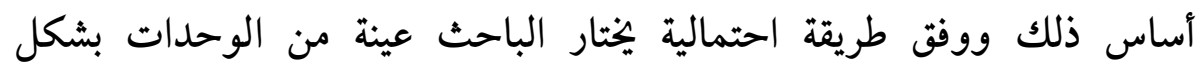

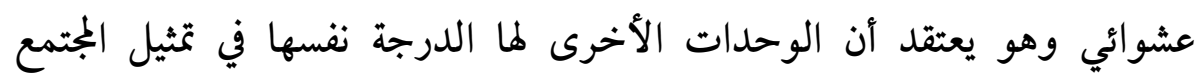

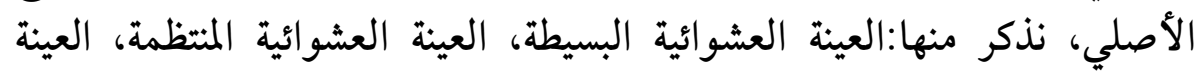

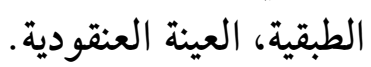

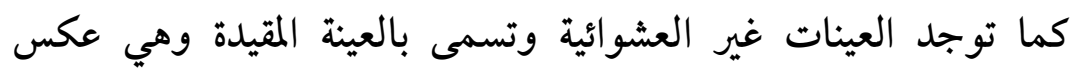

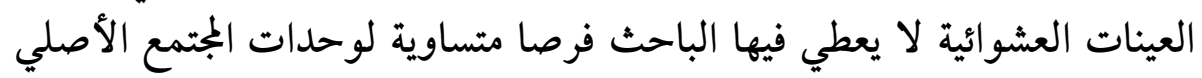

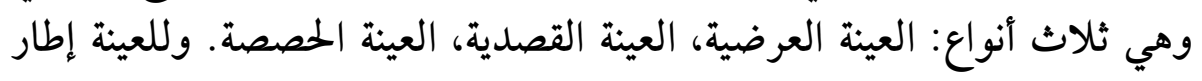

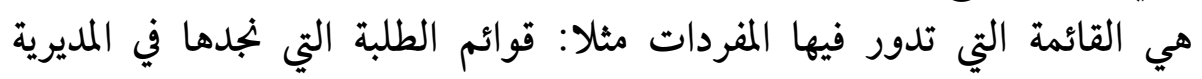

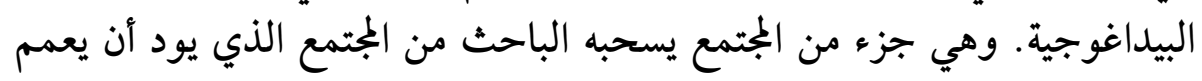

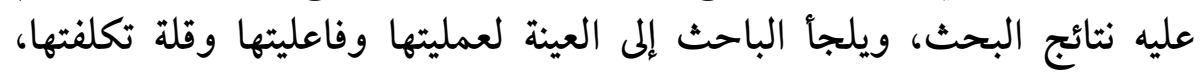

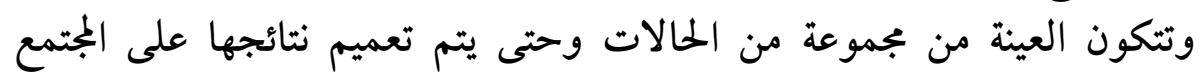
ينبغي أن تكون مثلة وتقتضي شرطين: ل أن تتوفر على خصائص المجتمع الذي سحبت منه. 


\section{ل أن تعطي الفرصة بالتساوي لجميع المفردات للظهور في العينة.}

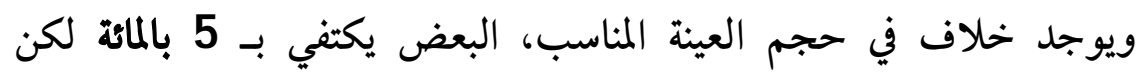

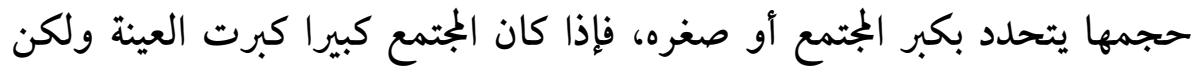

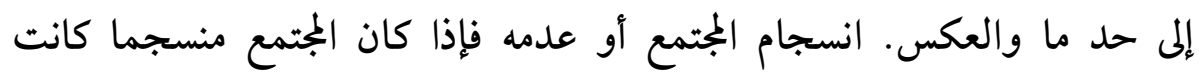
النتائج دقيقة والعكس مال والعكس. الن. سادسا / أدوات جمع البيانات 1 (1) - (استمارة

تعرف الاستمارة بأنها "تموذج يضم مجموعة أسئلة توجه إلى الأفراد من أجل الجمارد

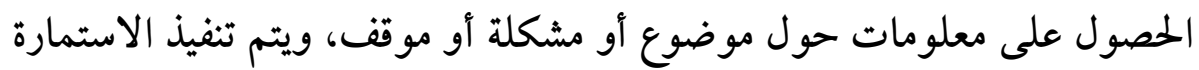

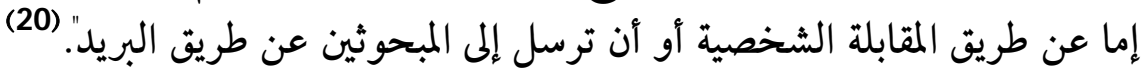

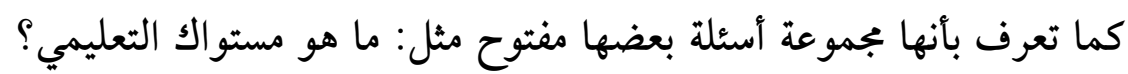

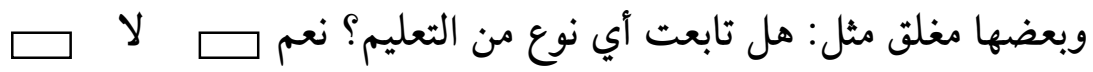
وبعضها أسئلة تصنيفية مفتوحة مثل:

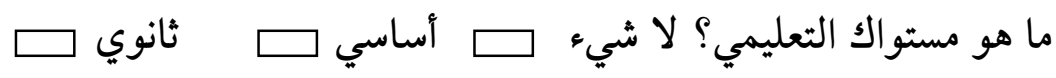

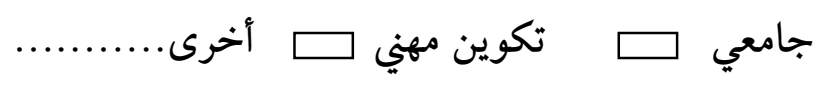

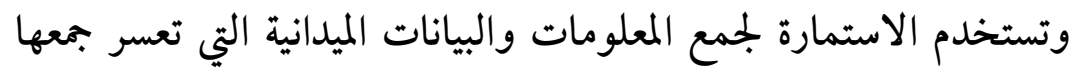

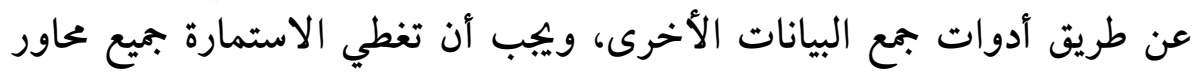

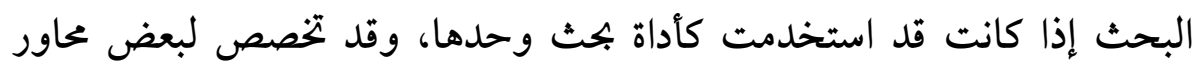

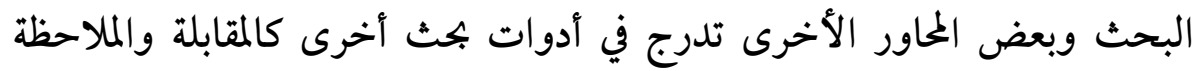
والوثائق والسجلات وبعض الإدارية.

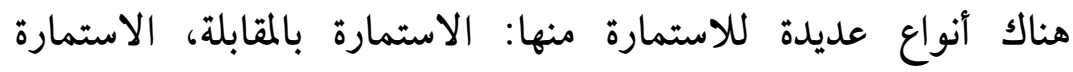
البريدية، الاستمارة عبر الماتف، الاستمارة عن طريق شبكة لإنة الإعلام الآلي

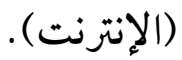




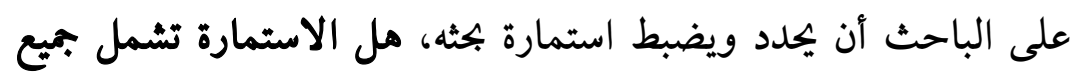

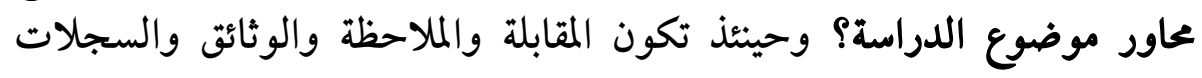

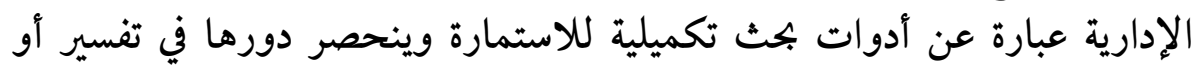

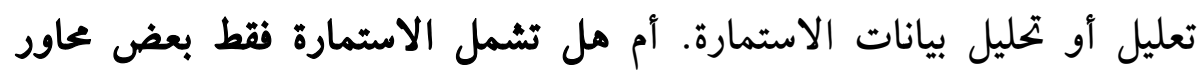

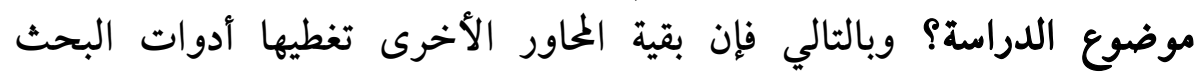

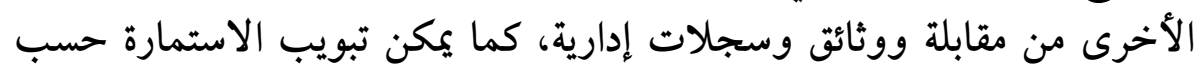

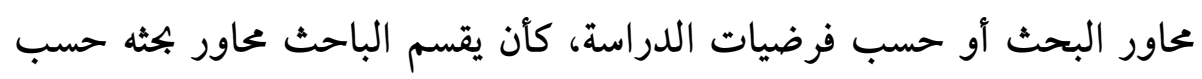

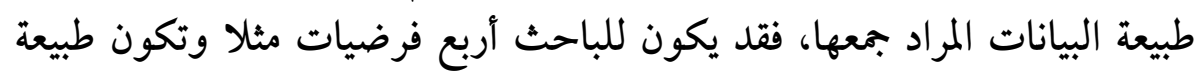

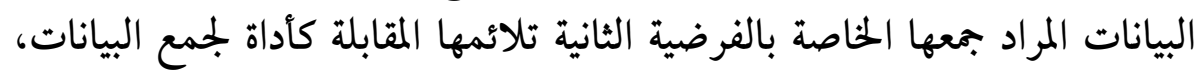

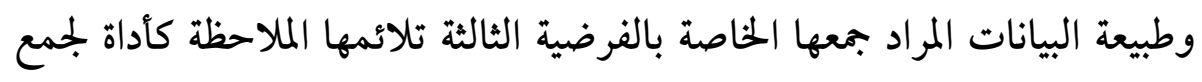

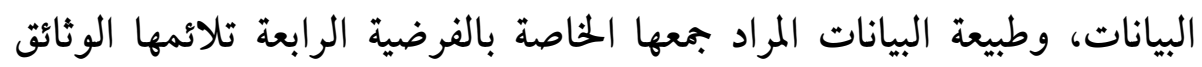

والسجلات الإدارية كأداة لجمع البيانات (21).

ويفضل أن يختبر الباحث استمارة بحثه ليرى مدى ملاءمة الإدة الاستمارة لمحاور

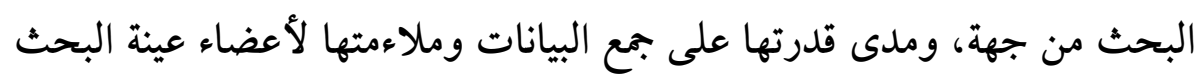

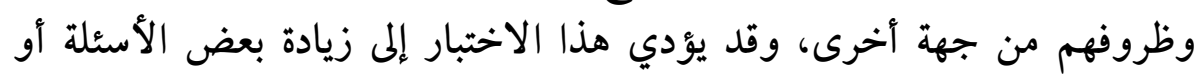

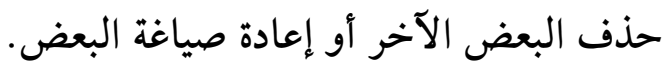

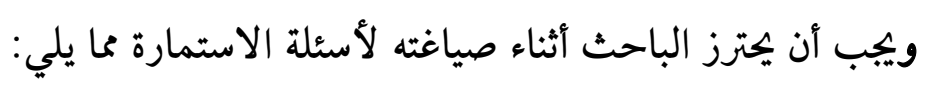

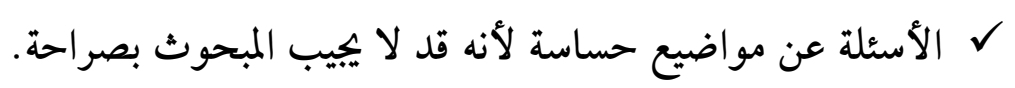

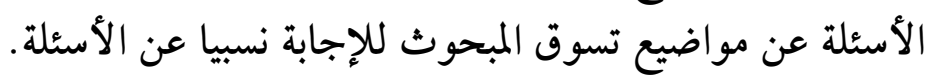

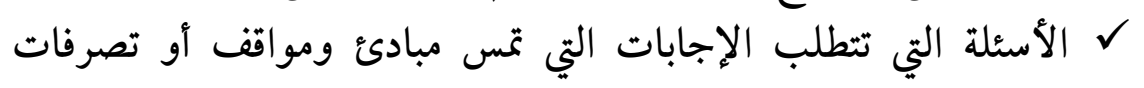
المبحوث. - الأسثلة التي

ل الأسئلة التي تسوق إلى أجوبة مضللة كأن ييجب المبحوث عن سؤال

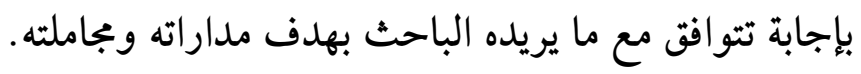


2) المقابلة

تعرف المقابلة على أنها: تفاعل لفظي يتم عن طريق موقف مواجهة يحاول فيه

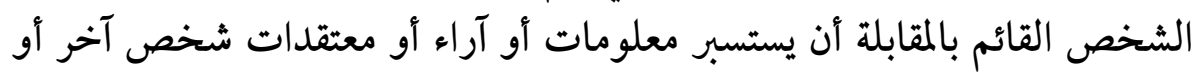
أشخاص آخرين للحصول على بعض المعلومات الموضوعية. (22) وتجري المقابلة في شكل حوار (حديث) مع المبحوث في موضوع البحث.

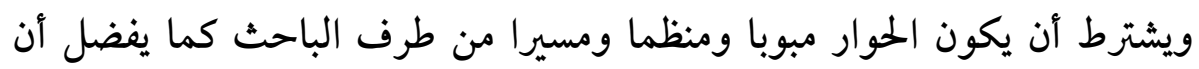
يقوم الباحث بتسجيل ملاحظات المبحوث وآرائه حول موضون ونوع البحث ونث. - أنواع المقابلة

المقابلة المقننة: وفيها يضع الباحث أسئلة كل محور في المقابلة. المقابلة غير المقننة: وفيها لا يضع الباحث أسئلة المحاور، إذ لا يقيد الحديث ولكن

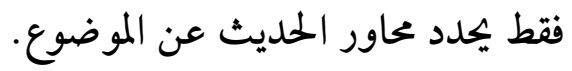

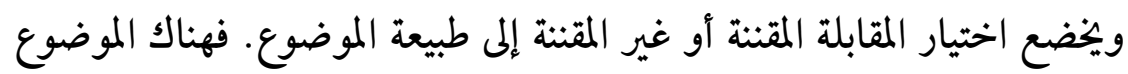

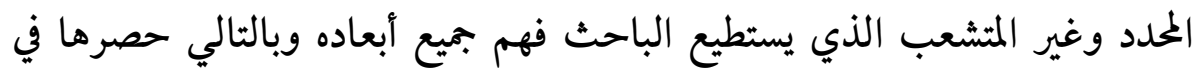

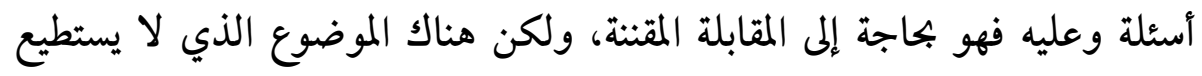
الباحث حصر أبعاده ولذلك يترك الحديث مفتوحا وبالتالي فهو بحاجة إلى المقابلة غير المقننة.

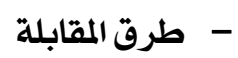

المقابلة المباشرة: وفيها يلتقي الباحث مع المبحوث مباشرة ويتم الحوار بشكل مباشر.

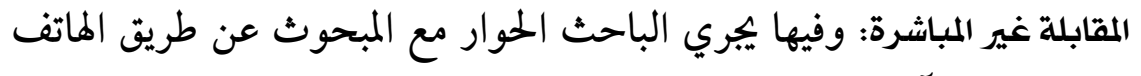

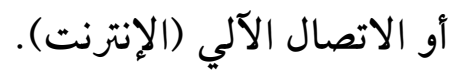

د- مميزات المقابلة: عموما تكون المقابلة مع عدد قليل من الأفراد، كما تتميز بإعطاء حرية الحديث للمبحوث والوقت الكافي، وحرية الحديث لا تعني أن يتكلم 
المبحوث كما يشاء وما يشاء، ولكن ييب أن تكون المقابلة مضبوطة ومحددة بدقة

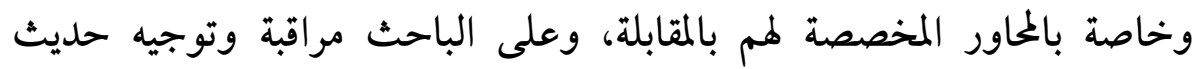

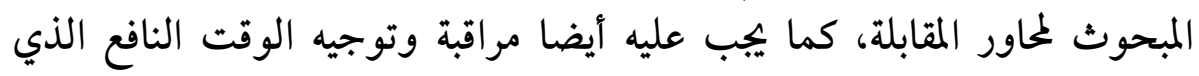

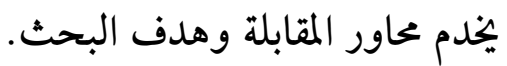

\section{3) الملاحظة}

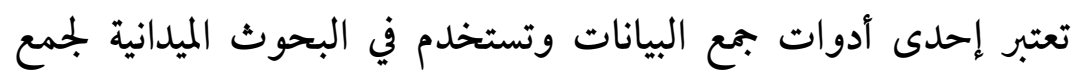

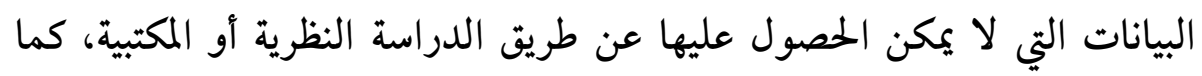

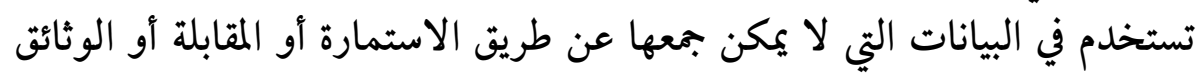

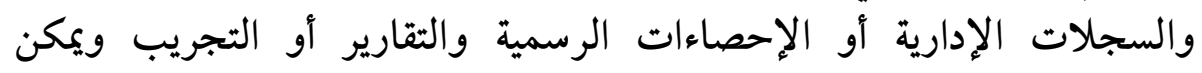

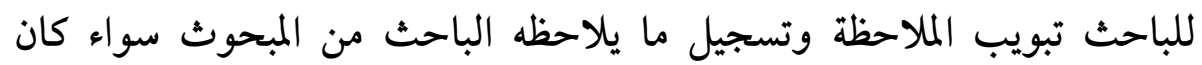

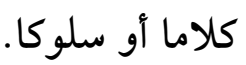

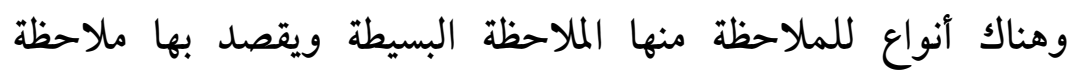

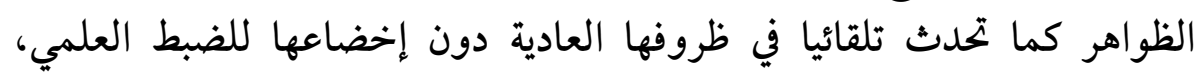

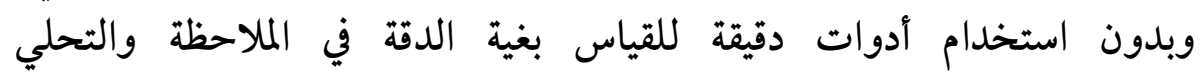

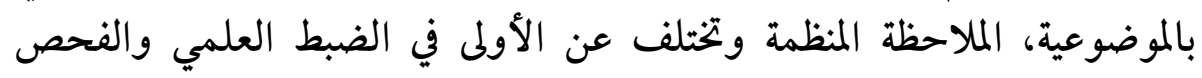

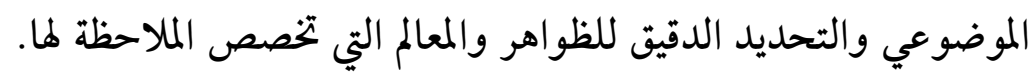

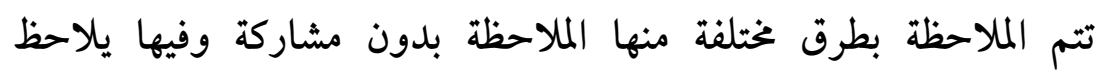

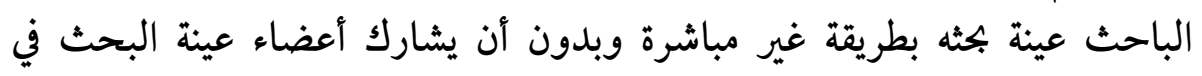

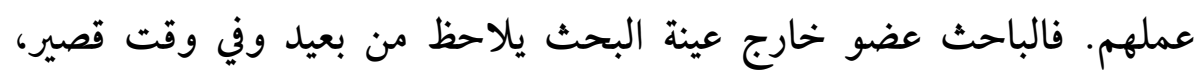

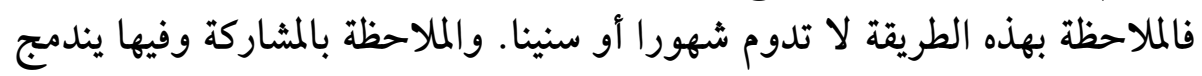

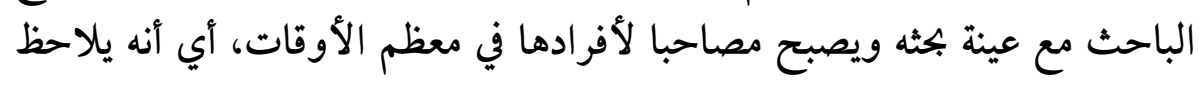

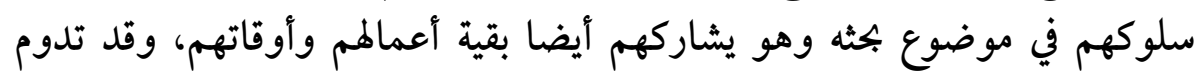

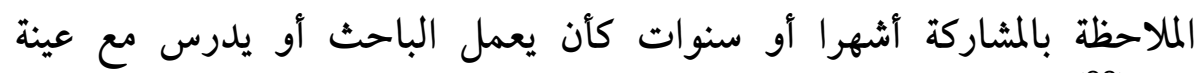
بحثه. (23) 
سابعا/ الوثائق والسجلات الإدارية: تعتبر إحدى أدوات جمع البيانات، وفيها

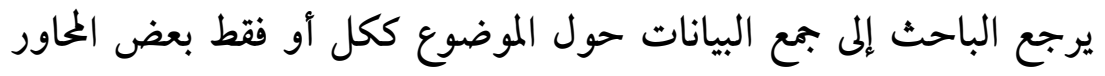

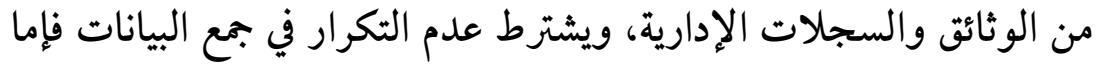
أن تكون البيانات المجمعة من الوثائق والسجلات ولات الإدارية بيانات تكميلية

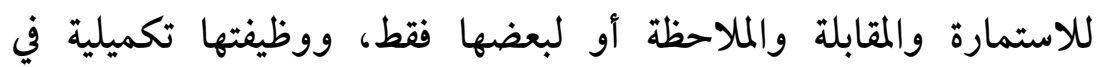

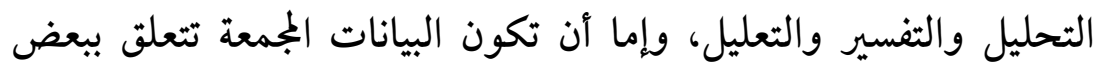
محاور البحث التي لا تمسهم أدوات جمع البيانات الأخرى. ثامنا/ الإحصاءات الرسمية والتقارير

خلاصة

نخلص في الأخير إلى القول أن البحث في العلوم الاجتماعية يحتاج إلى منهجية

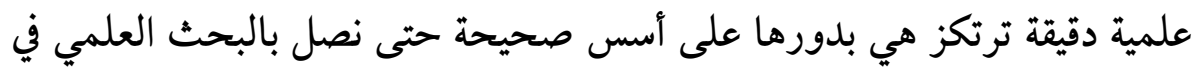

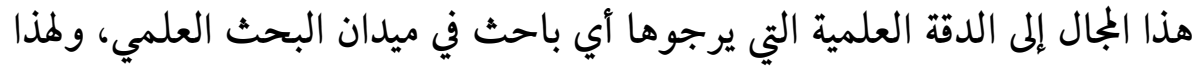

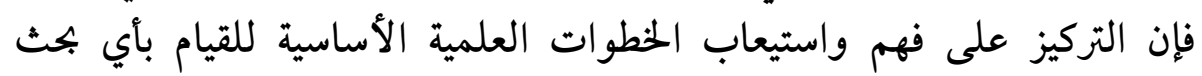

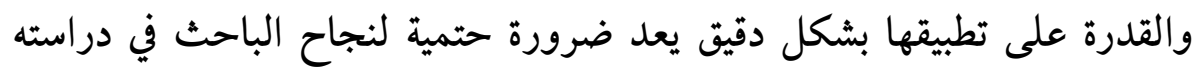
العلمية وتقديمها في صورة سليمة وميزة. 


\section{هوامش البحث}

فضيل دليو وآخرون: أس المنهجية في العلوم الاجتماعية، دار البعث، قسنطينة،

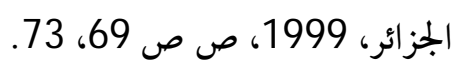

بلقاسم سلاطنية وحسان الجيلاني: منهجية العلوم الاجتماعية، دار الفجر للنشر

$$
\text { والمرجع نفسه، صوبع، مصر، 2012، ص } 95 .
$$

عبد الرحمان عدس وآخرون: البحث العلمي مفهومه وأدواته وأساليبه، دار الفكر

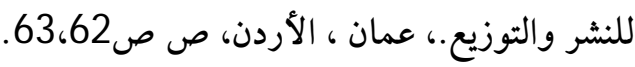

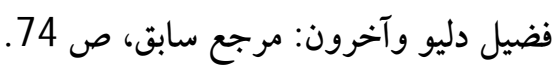

رؤوف إبراهيم عبد الخالق: التصاميم التجريبية في الدراسات النفسية والتربوية، دار صرار

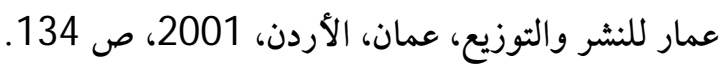
ربحي مصطفى عليان وآخرون: منامج واساليب البحث العلمي: النظرية والتطبيق،

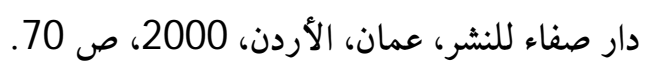

سالم عيسى بدر: دليل الباحث في اختبار الفرضيات، دار الفكر ، عمان، الأردن،

$$
\text { 2009، ص ص ص } 9 \text { ، } 15 .
$$

موريس أنجرس، منهجية البحث العلمي في العلوم الإنسانية، تدريبات عملية، ترجمة:

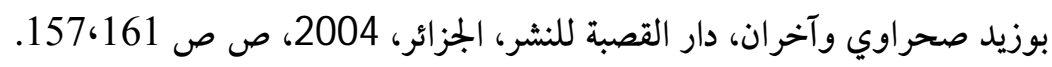

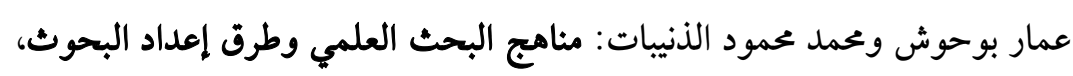

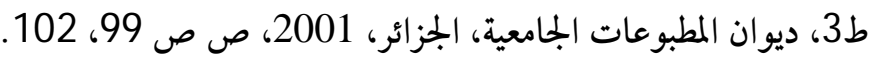

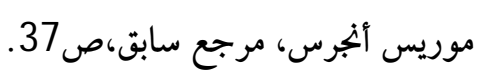

بلقاسم سلاطنية وحسان الجيلاني: المنامج الأساسية في العلوم الاجتماعية، دار

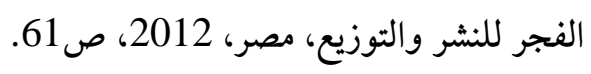

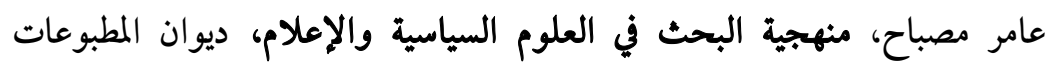

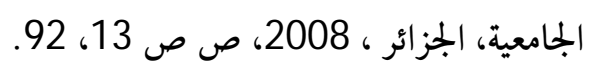


(14) بلقاسم سلاطنية وحسان الجيلاني: المنامج الأساسية في العلوم الاجتماعية، مرجع سابق، ص 42.

صلاح الدين شروح: منهجية البحث العلمي، دار العلوم للنشر والتوزيع، الجزائر،

$$
\text { 2003، ص ص صلاح الدين شروح: منهجية }
$$

بلقاسم سلاطنية وحسان الجيلاني: المناهج الأساسية في العلوم الاجتماعية، مرجع سابق، ص 28.

حسين عبد الحميد رشوان: العلم والبحث العلمي، دراسة في منامج العلوم، المكتب

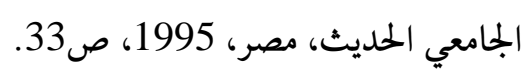

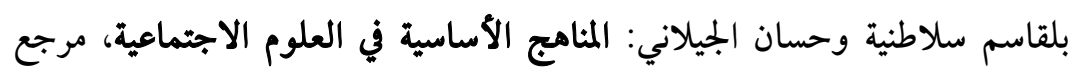

$$
\text { سابق، ص93. }
$$

محمد علي محمد: علم الاجتماع والمنهج العلمي، دار المعرفة الجامعية، الإسكندرية، صرحة

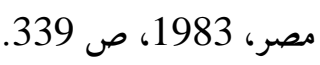

(21) DICTIONNAIRE DE SOCIOLOGIE. P436 LE ROBERT SEUIL.

إبراهيم لطفي: اساليب وأدوات البحث الاجتماعي، دار غريب للطباعة والنشر

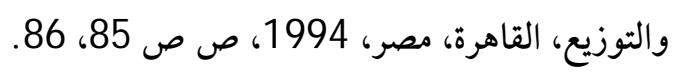

غريب محمد سيد أمد: تصميم وتنفيذ البحث الاجتماعي، دار المعرفة الجامعية، الإسكندرية، مصر، 1989، صريد اهمد: تصميم وتثفيل 268. 